San Jose State University

SJSU ScholarWorks

Master's Theses

Master's Theses and Graduate Research

Spring 2011

\title{
Effects of Water Conservation on Evapotranspiration in Las Vegas, Nevada
}

Joseph Belli

San Jose State University

Follow this and additional works at: https://scholarworks.sjsu.edu/etd_theses

\section{Recommended Citation}

Belli, Joseph, "Effects of Water Conservation on Evapotranspiration in Las Vegas, Nevada" (2011).

Master's Theses. 3911.

DOI: https://doi.org/10.31979/etd.afp9-gaek

https://scholarworks.sjsu.edu/etd_theses/3911

This Thesis is brought to you for free and open access by the Master's Theses and Graduate Research at SJSU ScholarWorks. It has been accepted for inclusion in Master's Theses by an authorized administrator of SJSU ScholarWorks. For more information, please contact scholarworks@sjsu.edu. 


\title{
EFFECTS OF WATER CONSERVATION ON EVAPOTRANSPIRATION IN LAS VEGAS, NEVADA
}

\author{
A Thesis \\ Presented to \\ The Faculty of the Department of Geography \\ San José State University \\ In Partial Fulfillment \\ of the Requirements for the Degree \\ Masters of Arts
}

by

Joe Belli

May 2011 
(C) 2011

Joe Belli

ALL RIGHTS RESERVED 
The Designated Thesis Committee Approves the Thesis Titled

EFFECTS OF WATER CONSERVATION ON EVAPOTRANSPIRATION IN LAS VEGAS, NEVADA

by

Joe Belli

APPROVED FOR THE DEPARTMENT OF GEOGRAPHY

SAN JOSÉ STATE UNIVERSITY

May 2011

Dr. Gary Pereira Department of Geography

Dr. Kathrine Richardson Department of Geography

Stephanie Hughes Santa Clara University 


\title{
ABSTRACT \\ EFFECTS OF WATER CONSERVATION ON EVAPOTRANSPIRATION IN LAS VEGAS, NEVADA
}

\author{
by Joe Belli
}

Las Vegas, Nevada, is a rapidly growing arid city that is experiencing significant challenges in water consumption. Most of the water is used outdoors, precluding recycling and reuse of water. With a large increase in population, the Southern Nevada Water Authority created the Water Smart Landscape Program to limit outdoor water usage. This study used remote sensing images and techniques to examine how much water was lost to the atmosphere through evapotranspiration (ET) in the Las Vegas metropolitan region from 1999 to 2009 . The results showed that both extreme weather conditions and water policy influence ET rates. 


\section{DEDICATION and ACKNOWLEDGEMENTS}

First and foremost, I would like to thank Dr. Pereira for all the advice, time, and

hard work he put into helping me with my master's thesis. Without him this work would not be possible. I would also like to give a big thanks to Dr. Richardson, Professor

Hughes, and Nikki Brown for the time they spent working with me on this document. This thesis is dedicated to my family for their love and support. 


\section{TABLE OF CONTENTS}

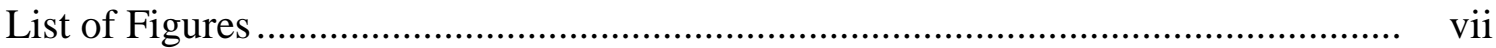

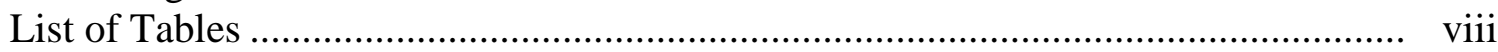

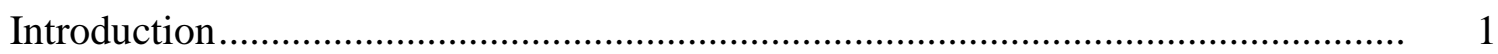

Las Vegas Water System ................................................................................ 2

Water Smart Landscape Program ...................................................................... 4

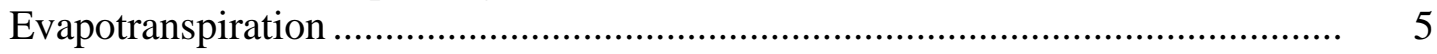

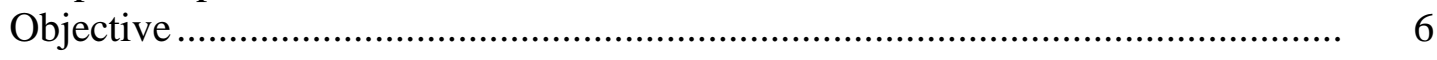

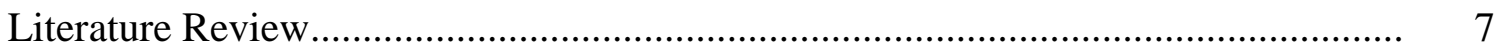

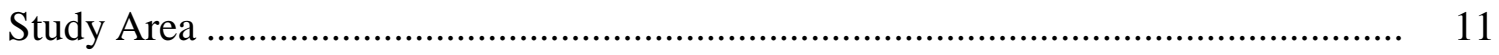

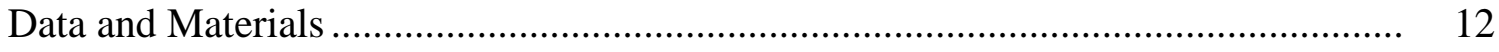

Software Used .................................................................................. 12

Data Preparation...................................................................................... 12

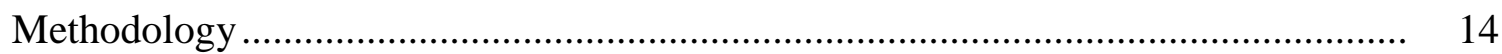

Tasseled Cap Transformation ........................................................................ 14

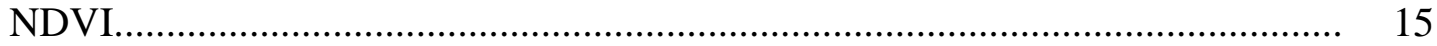

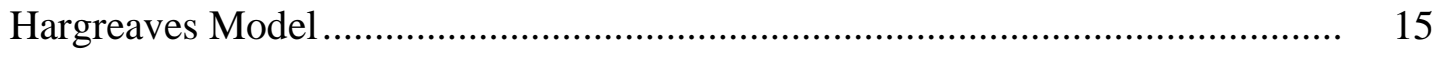

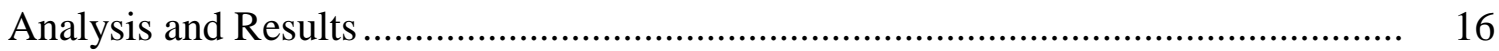

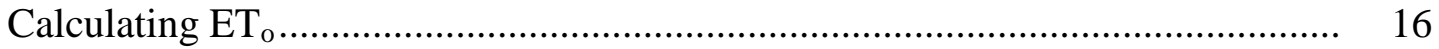

Classifying Urban Area for Analysis ............................................................... 16

Calculating ET for Each Year ........................................................................... 18

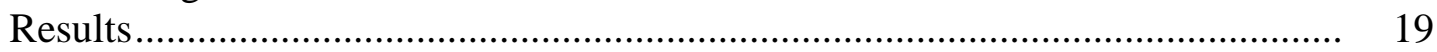

Discussion and Conclusion ................................................................................. 23

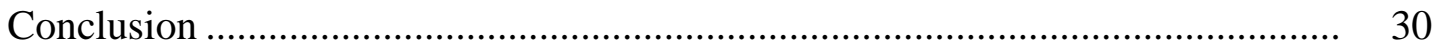

Appendix A: Wetness Histograms ..................................................................... 32

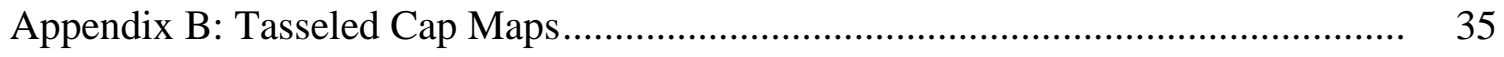

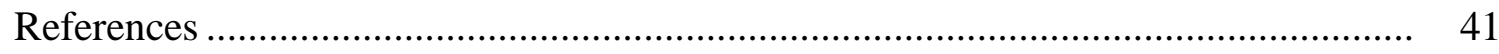




\section{LIST OF FIGURES}

Figure 1: Water Consumption in Southern Nevada in 2006 ................................ 2

Figure 2: Las Vegas Wash............................................................................. 3

Figure 3: Growth of Water Smart Landscape Program ........................................ 5

Figure 4: Study Area ..................................................................................... 11

Figure 5: Open Field, Canyon Gate Country Club, and Lake Mead ....................... 18

Figure 6: 2005 Wetness Tasseled Cap Histogram............................................... 22

Figure 7: Calculated ET Rates................................................................... 23

Figure 8: 2001 and 2002 Wetness Histograms ................................................ 24

Figure 9: 1999 and 2009 Modified Wetness Histograms ..................................... 26

Figure 10: Comparison of 1999 and 2009 Summerlin Tasseled Cap....................... 29

Figure 11: Las Vegas Metropolitan Population vs. ET .......................................... 30 


\section{LIST OF TABLES}

Table 1: Calculated $E_{0}$ Per Year .................................................................. 20

Table 2: $\quad$ ET Rates.................................................................................. 21 


\section{INTRODUCTION}

Las Vegas, Nevada, is currently facing major problems with water usage, availability, and conservation. Water in the region is harder to obtain and is being consumed at higher rates due to the steady growth in population. Within the last twenty years, Las Vegas has experienced a large population boom, making it one of the fastest growing cities in the United States. At the moment, the Las Vegas metropolitan area has over 1.9 million people (City Data, 2010). The population is projected to grow by 80,000-90,000 people annually through 2013 (Krystyna, 2001). The large population combined with the hot and arid climate creates major problems for water availability and consumption. With a projected increase in temperature and drought for the region, water resources are expected to be in even greater demand in the near future. In Las Vegas, planning and conservation methods are being employed to limit the consumption of water. Minimizing outdoor water usage is a key conservation goal since most water is used for landscaping.

As of 2006, residential properties accounted for 59\% (Figure 1) of water usage in Las Vegas (SNWA, 2010). Surprisingly, casinos and golf courses consumed only 14\% of total water usage, while industrial and commercial usage was at 13\% (SNWA, 2010). The remaining percentage represented schools, parks, and common areas. According to the Southern Nevada Water Authority (SNWA), all outdoor water usage accounted for $60 \%$ of total water usage in the area (SNWA, 2010). The SNWA implemented the Water Smart Landscape Program, which gives rebates to property owners who convert from thirsty grass to more water-efficient desert landscaping. 


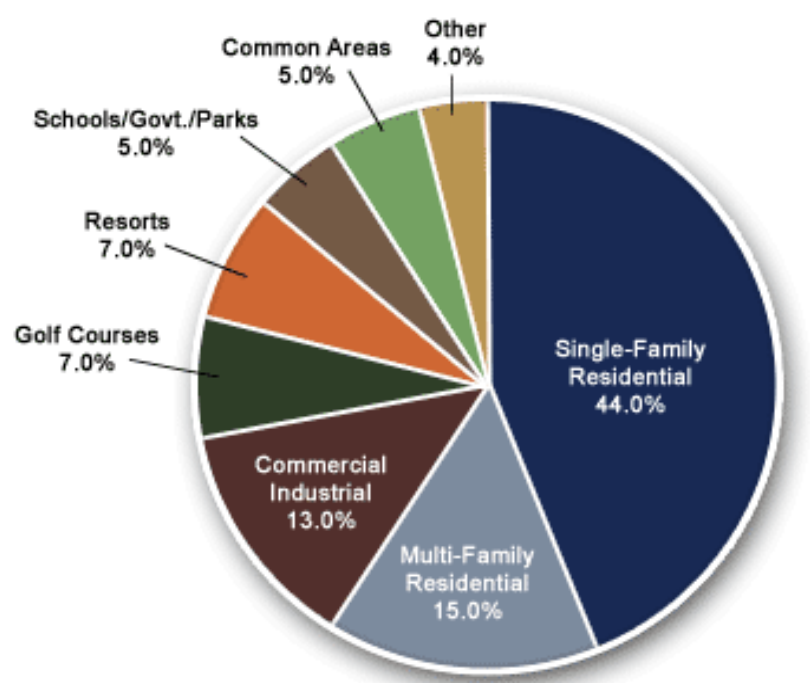

Based upon 2006 municipal metered potable and non-potable water use in the Southern Nevada Water Authority's metered service area.

Figure 1: Water Consumption in Southern Nevada in 2006 (SNWA, 2010)

\section{Las Vegas Water System}

The majority of Las Vegas' water comes from Lake Mead, located east of the city. Lake Mead provides around $88 \%$ of the water supply for the region (LVWCC, 2000). Six states and Mexico share water from the Colorado River, which delivers Lake Mead its water. Water withdrawals for Las Vegas are limited by law to a maximum of 300,000 acre-feet per year $\left(3.7 \times 10^{\wedge} 8 \mathrm{~m}^{3}\right)(\mathrm{LVWCC}, 2000)$. Credit is provided for any water returned to Lake Mead through wastewater treatment plants. Any unused water that flows into the sewer from activities such as showering or washing cars travels to a wastewater treatment plant. The treated water is then returned to Lake Mead through the Las Vegas Wash (Figure 2) where it is credited. The ability to reuse water extends the resource of Lake Mead. Any water lost to the atmosphere from watering lawns cannot be reused and thus depletes water resources in the region. According to the SNWA, $60 \%$ of 
water delivered to residents is used only once and most of that percentage is for landscape irrigation (SNWA, 2009).

Drought conditions have occurred in Las Vegas within the last ten years, causing a big concern for water availability. In early 2009, the total water storage of Lake Mead was only $52 \%$ of its total capacity (SNWA, 2009). Drought continues to push Las Vegas to the limit of its water supply. For Las Vegas to continue to supply its residents with an adequate amount of water, it is extremely critical to sustain high water levels in Lake Mead; to do so, limiting water lost to the atmosphere as well as maximizing recycling of water are very important.

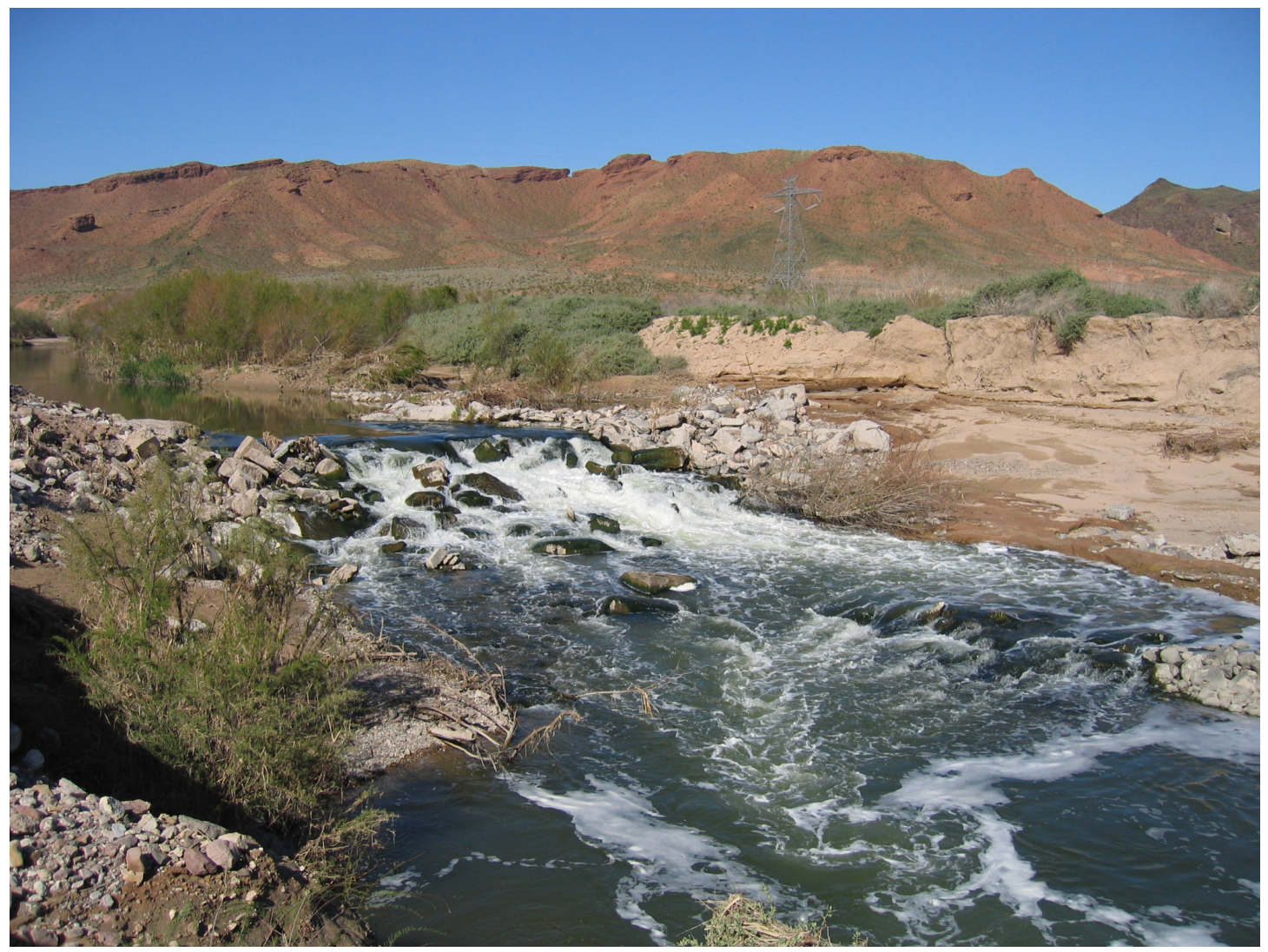

Figure 2: Las Vegas Wash (City of Henderson, 2010) 


\section{Water Smart Landscape Program}

The Water Smart Landscape Program of the SNWA is a program used to decrease water consumption and water lost to the atmosphere through soil and lawns. The program pays $\$ 1.50$ for every square foot of grass converted to native vegetation. To avoid creating heat islands with exclusive rock gardens, $50 \%$ of the land converted must be canopy coverage (Sovocool, 2005). Although the program is focused on residential properties, it also includes other types of properties, such as shopping centers, business parks, and golf courses. A single business could make up to a maximum of $\$ 300,000$ in rebates in a single year (Sovocool, 2005). To be eligible for a rebate, a minimum size of 400 square feet of lawn must be converted to natural vegetation. Although less common, properties under 400 square feet of lawn can still be accepted if they eliminate an entire front or back lawn of a residential unit or if they completely eliminate a lawn on a commercial, industrial, or institutional property.

The Water Smart Landscape Program was implemented in 1999. From July 2000 to July 2004 , the program increased to $3,400,000$ square feet rebated per month (Figure 3). On average, the total area of one property converted to a natural landscape was 2,162 square feet (Sovocool, 2005). It has been estimated that converting lawns to a natural landscape saves 55 gallons of water per year per square foot, or an average of 118,910 gallons of savings per property per year (SNWA, 2009). 


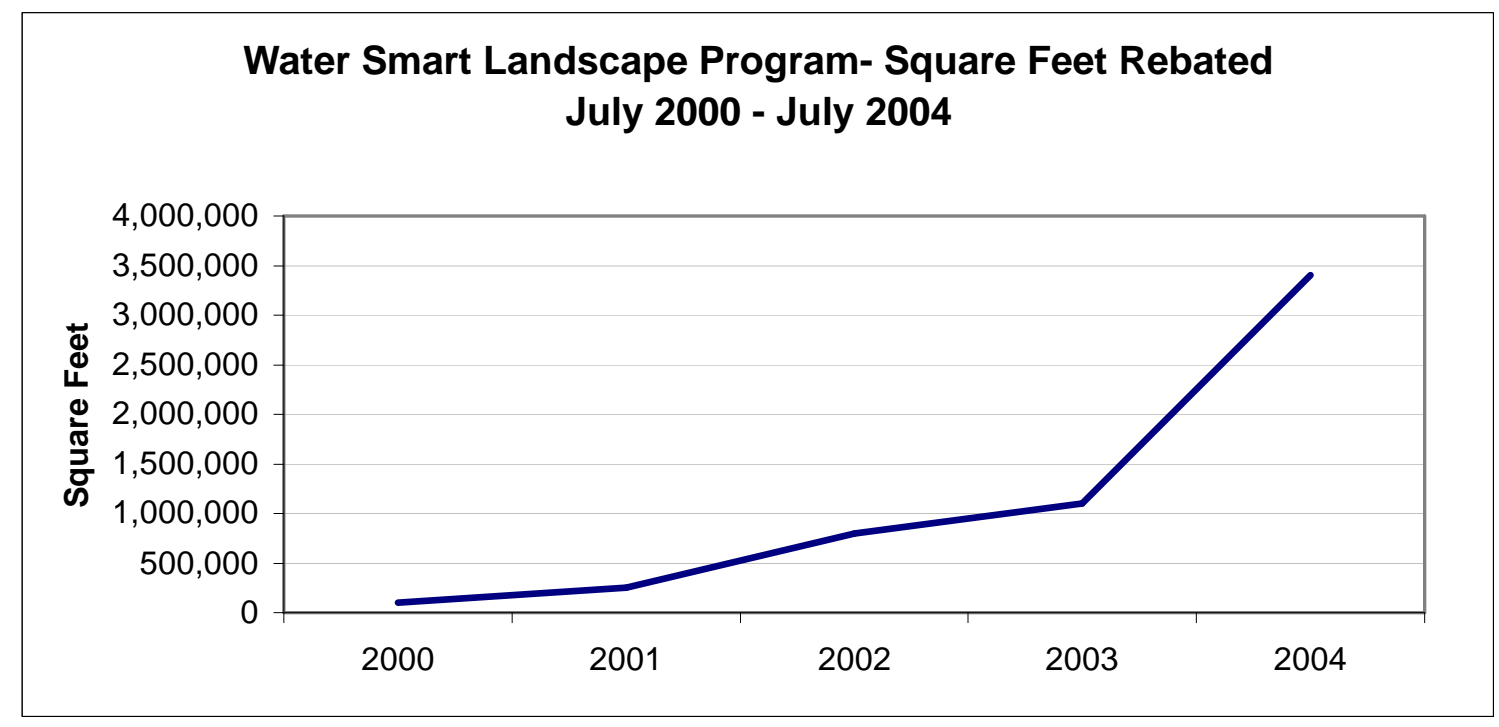

Figure 3: Growth of Water Smart Landscape Program

\section{Evapotranspiration}

Evapotranspiration (ET) is the physical process whereby water is lost from the ground surface, including from both the soil and the vegetation, to the atmosphere as vapor. ET is the sum of evaporation and transpiration and is one of the main consumers of energy at the earth's surface. Potential evapotranspiration $\left(\mathrm{ET}_{\mathrm{o}}\right)$ is the maximum amount of ET that would occur given accurate weather conditions. In hot and arid climates, ET can be magnified during the summer months. During a drought, ET is intensified because ET continues to deplete the limited remaining water supplies in soil, lakes, and streams. ET is a major reason why a vast amount of water is lost to watering and maintaining lawns; water that could otherwise run off and be recycled is lost to the atmosphere through ET. 


\section{Objective}

The objective of this study was to determine whether Landsat satellite data could be used to estimate ET in light of the Water Smart Landscape Program in Las Vegas, Nevada. This study examined July data over an 11-year span from 1999 to 2009 using remote sensing techniques. It was hypothesized that the Landsat satellite images would be able to provide adequate ET results, even with limited meteorological data. In doing so, the ET results may provide an indication of how well the Smart Water Landscape Program has done. If the Smart Water Landscape program is successful, it is expected that ET rates will not have significantly increased, despite urban growth, in recent years. 


\section{LITERATURE REVIEW}

Obtaining accurate information on water consumption is extremely important for water resource managers. Water distribution is already a major issue for many cities around the world. As populations continue to increase, managing water will be even more critical. For many environmental monitoring applications, including water resource management, understanding the distribution of ET is extremely critical (Batra et al., 2006). ET is not only vital for monitoring irrigation performance but also in evaluating water productivity. ET allows for water managers to help predict and accurately assess water usage because ET is one of the most useful indicators for determining whether water is being used correctly (Mutiga et al., 2009).

Achieving direct measurements of actual ET can be difficult; it is easier to do when the study area is small because in most cases direct measurements, as in data gathered from weather stations, provide only point values (Mutiga et al., 2009). When studying a large area, using direct measurement proves challenging because a lot of the land may be missed in the measurement; instead, using direct measurement to validate another form of measurement is a better technique to study ET. Although ET is one of the most important factors in a water cycle, it is usually one of the most difficult to measure (Mutiga et al., 2009). Currently, the most common way to measure ET is through remote sensing data. Remote sensing techniques can combine important determining factors such as soil temperature, vegetation cover, vapor pressure, and wind speed to obtain ET values (Batra et al., 2006). For estimating large-scale areas, remote sensing has been proven to be the only appropriate technique because it is the only 
technology that can provide representative parameters (Li and Lyons, 2002). Using remote sensing techniques to estimate ET continues to grow with new advances. Significant progress has been made within the past three decades to estimate ET (Mutiga et al., 2009). Today, computing ET from a small pixel scale to that of an entire valley is possible. In sum, the advances of remote sensing have made calculating ET values easier for researchers.

When computing ET values from remote sensing devices, the most common data come from Landsat Thematic Mapper (TM) imaging sensors. Spectral bands 1 through 7 are used from the Landsat sensors. Spectral bands 1 through 5 and 7 provide data for short-wave visible and near-infrared bands. Spectral band 6 provides data on thermal radiation (Folhes et al., 2009). A regional spatial coverage and resolution of 30 meters for each scene provides for the optimal estimation of ET. The majority of studies encountered throughout the literature surveyed used 30-meter resolution. When computing ET from remote sensing images, using cloud-free images is essential; clouds in the atmosphere act as barriers that block views of the surface.

Algorithms are the main method used to calculate ET values from remote sensing devices. A number of different algorithms and techniques have been proposed; however, three common methods are the Surface Energy Balance Algorithm for Land (SEBAL), Mapping Evapotranspiration at High Resolution and with Internalized Calibration (METRIC), and the Penman-Monteith approach. SEBAL was developed by Bastiaanssen in 1995 and has been applied to many semi-arid and arid regions all over the world (Folhes et al., 2009). Data from the visible, near infrared, and thermal bands are all used 
in SEBAL. The algorithm uses energy balance to compute ET. The energy driving the water cycle is equal to the incoming energy minus the energy reflected back to space and the energy heating the ground soil (Mutiga et al., 2009).

The METRIC approach is an energy balance model for estimating ET and is an extended modification of the widely accepted SEBAL. METRIC predicts ET by the calculation of the energy balance at the surface, which is done on a pixel-by-pixel basis for the direct time the satellite overpasses (Folhes et al., 2009). Since the image provides information only for the time the satellite overpasses, METRIC computes ET for the moment the image is captured.

The Penman-Monteith equation is another energy balance approach to estimate ET. The equation requires temperature, relative humidity, wind, saturated vapor pressure, and net radiation to calculate ET (Wu, 1997). The Penman-Monteith is highly recommended and frequently used because of its accommodation of small time periods and of its comprehensive theoretical base. However, the equation requires a substantial amount of meteorological data while using extensive calculations and extremely detailed unit conversions. In many cases the meteorological data may not be available for the region.

The Hargreaves model is an excellent and commonly used model to calculate $\mathrm{ET}_{\mathrm{o}}$ rates. The model is widely used because it is a simpler model that requires only two parameters, average temperature and incident solar radiation, which is the total amount of solar energy a location receives a day (Wu, 1997). Unlike most ET models, the Hargreaves equation does not require complex meteorological data (Hargreaves and 
Samani, 1982). Since incident solar radiation and temperature are easy to obtain, the Hargreaves model is a simple and efficient method to calculate $\mathrm{ET}_{\mathrm{o}}$ anywhere in the world.

The SNWA performed a Xeriscape Conversion study in 2005 to examine how much cultivated grass was being converted to native vegetation, without the use of remote sensing techniques. The main goal of the study was to determine water saving estimates. The study used hundreds of participants as well as installation of submeters to collect and analyze the data. Using statistical methods, the SNWA found a total savings of $30 \%$ (96,000 gallons) for annual residential consumption for those who converted from grass to native vegetation (Sovocool, 2005). Savings were most evident in the summer months when more water is needed to irrigate lawns. The study also experimented with the local principle that implies that native vegetation planting requires one-third the ET rate needed for grass; the Xeriscape Conversion study found this proportion to be accurate. 


\section{STUDY AREA}

The study area encompasses the entire Las Vegas metropolitan area, located in the central portion of Clark County, Nevada. The coordinates for the Las Vegas metropolitan area are $115^{\circ} 19^{\prime} 30.90^{\prime \prime} \mathrm{W}$ to $-115^{\circ} 19^{\prime} 01.34^{\prime \prime} \mathrm{W}$ and $36^{\circ} 20^{\prime} 28.14^{\prime \prime} \mathrm{N}$ to - $36^{\circ} 20^{\prime} 03.39^{\prime \prime} \mathrm{N}$. The study area includes Boulder City, which is situated 20 miles southeast of Las Vegas (Figure 4).

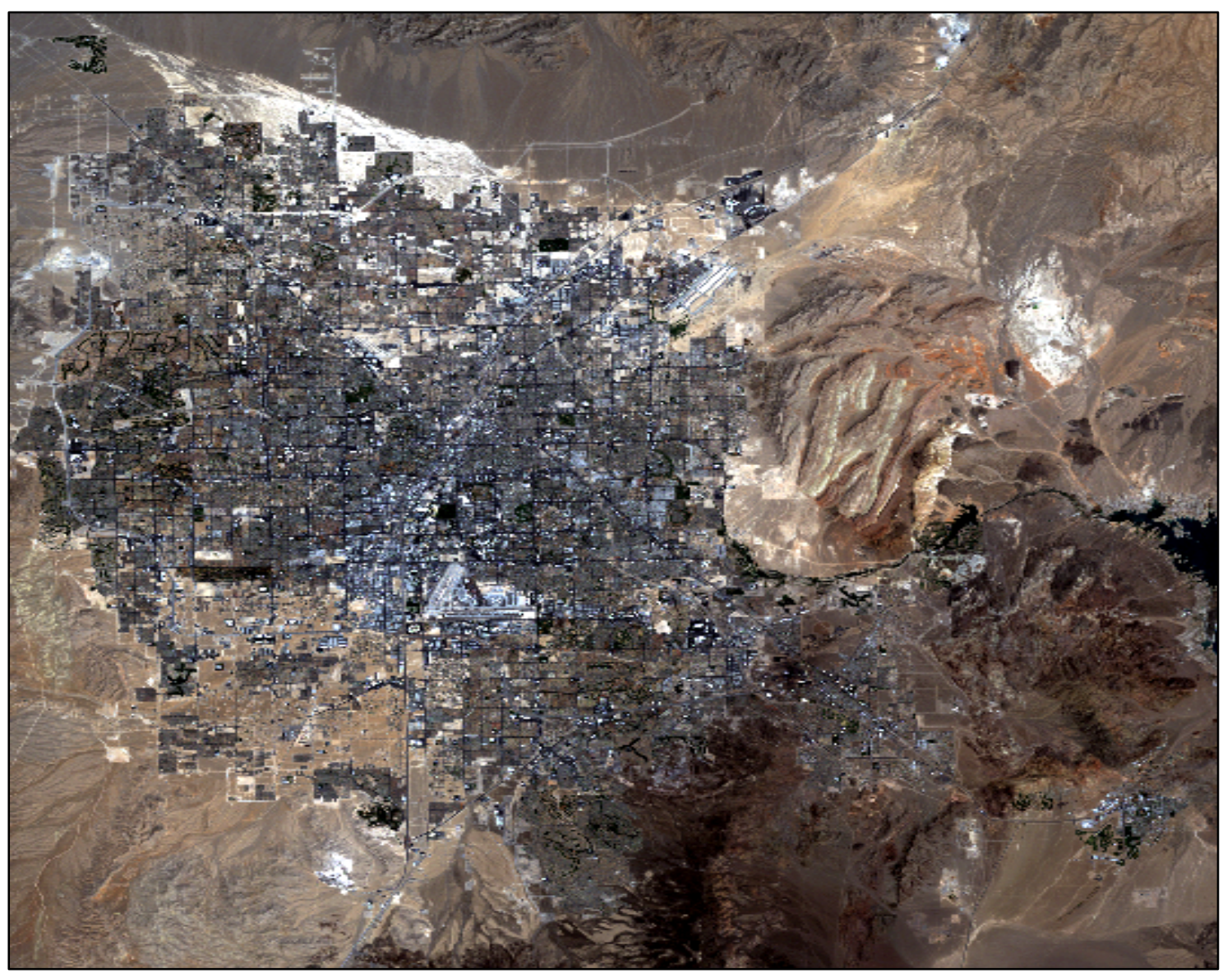

Figure 4: Study Area 


\section{DATA AND MATERIALS}

The data used for the analysis consist of Landsat remote sensing scenes of the Las Vegas region in July from 1999 to 2009. The exact date within July that the scenes were captured varies between the years, but all captured scenes occurred in early portions of the months. July provided the most accurate analysis because ET rates are the highest in the hottest month of the year. The data was obtained using the USGS Global Visualization Viewer. The remote sensing scenes were all Landsat 7 scenes with the satellite flight path 39 and the row 35 . Each year's data came with remote sensing bands 1 to 7 , with the exception of the year 2000 that did not included band 7 .

\section{Software Used}

The main software used for the analysis was IDRISI. The primary use of IDRISI is to process geospatial raster data. IDRISI is one of the leading software programs for geospatial and remote sensing data. The software offers a number of different tools and options for users to analyze imagery. IDRISI uses advanced remote sensing analysis and spatial modeling to create new information. Both remote sensing and geographic information systems capabilities are incorporated in the software to allow for the creation of geospatial data as well as the extraction of important information from the data.

\section{Data Preparation}

In order to begin the analysis, a number of steps were required to prepare the data. After downloading the remote sensing bands, the data were converted into the GeoTIFF format so that IDRISI could import it. The remote sensing images included a lot of nonurban area in Clark County that did not pertain to this study. To simplify the analysis, the 
remote sensing layers were windowed to only include the urban area of Las Vegas.

Every band for every year was windowed to the study area. 


\section{METHODOLOGY}

The analysis used different remote sensing techniques to help determine the ET rates in Las Vegas from 1999 to 2009; each technique focused on different features of remote sensing. Since each technique studied a unique aspect of the physical landscape, the results are completely distinctive to the individual method. Incorporating the results for the three techniques helped to estimate ET rates. The techniques used were the tasseled cap transformation, normalized difference vegetation index (NDVI), and the Hargreaves Model.

\section{Tasseled Cap Transformation}

The tasseled cap transformation is an algorithm that converts the original bands of an image into a new set of bands or variables. The parameters are different depending on remote sensing satellite. For Landsat TM, the parameters used for Landsat 7, the original bands are transformed into three variables that measure physical characteristics of the landscape. The three variables are brightness $(B)$, greenness $(G)$, and wetness $(W)$. The tasseled cap transformation is often used as a vegetation index to measure the amount of soil brightness, vegetation, and wetness content for each pixel in the image (Jensen, 2007). A tasseled cap transformation was created in IDRISI for every year in the study and is presented in Appendix B. The equation for Landsat TM is:

$$
\begin{aligned}
& \mathrm{B}=0.2909 \mathrm{TM}_{1}+0.2493 \mathrm{TM}_{2}+0.4806 \mathrm{TM}_{3}+0.5568{ }_{\mathrm{TM} 4}+0.4438 \mathrm{TM} 5+0.1706 \mathrm{TM} 7 \\
& \mathrm{G}=-0.2728_{\mathrm{TM} 1}-0.2174_{\mathrm{TM} 2}-0.5508_{\mathrm{TM} 3}+0.7221_{\mathrm{TM} 4}+0.0733_{\mathrm{TM} 5}-0.1648_{\mathrm{TM}} \\
& \mathrm{W}=0.1446_{\mathrm{TM} 1}+0.1761_{\mathrm{TM} 2}+0.3322_{\mathrm{TM} 3}+0.3396_{\mathrm{TM} 4}-0.61 \mathrm{TM}_{\mathrm{TM}}-0.4186_{\mathrm{TM} 7}
\end{aligned}
$$

where ${ }_{\mathrm{TMx}}=$ the Landsat Thematic Mapper band number $\mathrm{x}$. 
NDVI is a remote sensing equation used to assess live vegetation of an area. The equation is a ratio that produces a range of values from zero to one. Values closer to zero correspond to barren areas lacking water, whereas values closest to one are areas with water. Many scientists continue to use NDVI for Landsat remote sensing data. Both seasonal and inter-annual changes in vegetation growth can be monitored using NDVI. Chlorophyll is responsible for producing the green color in plants by absorbing the red light and reflecting the green. To calculate NDVI, the red band (band 3) is subtracted from the reflectance in the near-infrared band (band 4) and is then divided by the sum of the red band and the near-infrared band. The equation is written as:

$$
\mathrm{NDVI}=(\mathrm{NIR}-\mathrm{RED}) /(\mathrm{NIR}+\mathrm{RED})
$$

The results show the amount of live vegetation growing in a particular area. For this study the NDVI equation is derived as:

$$
\text { NDVI= (TM 4-TM 3)/(TM 4+TM 3) }
$$

\section{Hargreaves Model}

As mentioned, the Hargreaves Model is a simplified model that requires only temperature and solar energy to calculate $\mathrm{ET}_{\mathrm{o}}$ rates. The model is expressed as:

$$
\mathrm{ET}_{\mathrm{o}}=0.0135(\mathrm{~T}+17.78) \mathrm{R}_{\mathrm{s}}
$$

where $\mathrm{ET}_{\mathrm{o}}=$ potential daily evapotranspiration, in $\mathrm{mm} /$ day; $\mathrm{T}=$ mean temperature, in degrees Celsius; and $\mathrm{R}_{\mathrm{s}}=$ incident solar radiation, in either megajoules per square meter or Langley per day. The result of $\mathrm{ET}_{\mathrm{o}}$ is expressed as a unit of $\mathrm{mm} / \mathrm{day}$. 


\begin{abstract}
ANALYSIS AND RESULTS
The analysis first calculated the $\mathrm{ET}_{\mathrm{o}}$ using the Hargreaves Model. The tasseled cap transformation for wetness was then used to classify urban areas for the analysis. The calculated $\mathrm{ET}_{\mathrm{o}}$ was reapplied to help estimate ET rates. Calculating $E T_{o}$
\end{abstract}

The $\mathrm{ET}_{\mathrm{o}}$ rates were calculated using the Hargreaves model. Mean temperature values for the specific date in each year of the study were derived from data obtained by Weather Underground. The same weather station in Las Vegas was used for each year to maintain consistency. The Hargreaves model also requires incident solar radiation in either megajoules per square meter or Langley per day. The average incident solar radiation for Las Vegas in July is $7.37 \mathrm{kWh} / \mathrm{m}^{2} /$ day (NASA, 2010). When converted, the average incident solar radiation for Las Vegas in July is $26.53 \mathrm{MJ} / \mathrm{m}^{2} /$ day. The average incident solar radiation was kept constant at $26.53 \mathrm{MJ} / \mathrm{m}^{2} /$ day for each year of the study, due to the lack of daily solar radiation data. Once the average daily temperature and incident solar radiation were obtained, the Hargreaves model using megajoules per square meter was applied to every year. The equation used was:

$$
\mathrm{ET}_{\mathrm{o}}=0.0135(\mathrm{~T}+17.78) \mathrm{R}_{\mathrm{s}}(238.8 / 595.5-0.55 \mathrm{~T})
$$

where $\mathrm{R}_{\mathrm{s}}=$ incident solar radiation, in $\mathrm{MJ} / \mathrm{m}^{2} /$ day and $\mathrm{T}=$ average daily temperature, in degrees Celsius.

Classifying Urban Area for Analysis

To calculate ET rates for the Las Vegas metropolitan area, urban areas needed to be distinguished from non-urban desert land. An open field with latitude and longitude 
coordinates $36^{\circ} 6^{\prime} 23.0538^{\prime \prime} \mathrm{N}$ to $-115^{\circ} 16^{\prime} 11.9856^{\prime \prime} \mathrm{W}$ (red point on Figure 5) was set as the minimum wetness value for each year. The open field was selected as the minimum value because in the tasseled cap transformation for wetness the field perfectly represented values associated with dry, arid land. The field was also located within the city and was visible in each year of this study. Any wetness values below the minimum open field value for each year were not used in the analysis. A two-step process occurred to obtain the maximum wetness values for each year. The maximum wetness value for each year is the value where $\mathrm{ET}$ is at the highest and is equal to the $\mathrm{ET}_{0}$. In most cases open bodies of water will have the highest ET rate. For each year, the wetness value of Lake Mead (yellow point on Figure 5) was taken from the tasseled cap transformation. To increase accuracy, the wetness value of the Canyon Gate Country Club golf course (green point on Figure 5) was taken as well. Canyon Gate Country Club was used because lawns have extremely high ET rates and country clubs are known to maintain and water their courses very well. The mean of the wetness values from Lake Mead and the Canyon Gate Country Club were used as the maximum wetness value for each year. Any values above the maximum value were not used in the analysis. 


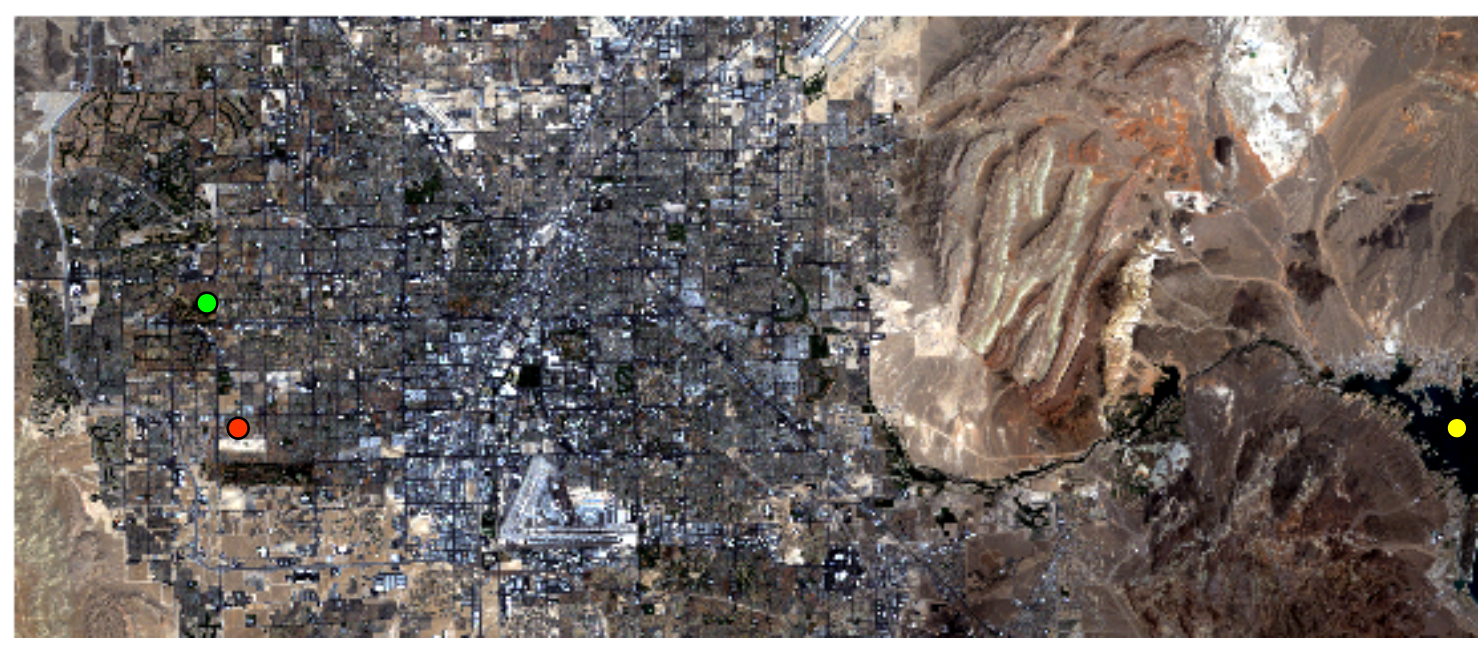

Figure 5- Open Field, Canyon Gate Country Club, and Lake Mead

\section{Calculating ET for Each Year}

After classifying which areas would be used for the analysis, the next step was to take the wetness values from the tasseled cap transformation and convert them to meaningful units of measure to calculate ET rates. The tasseled cap transformation wetness histograms for each year were imported into Microsoft Excel for calculations. The wetness values from the tasseled cap transformation for each year were scaled down and assigned a new value between zero and one. The minimum wetness value, in the open field, was given a new value of zero. The maximum value of one was derived by taking the mean of the Canyon Country Club and Lake Mead; any values equal to the mean were assigned one. Creating a mean saturates at the high end, in open water, so that landscape values are better represented. Values between zero and one were normalized at equal intervals. The equal intervals were calculated by dividing the number of wetness values from the tasseled cap transformation by one for each year. Once the wetness values were normalized to a new value between zero to one, the new 
values were multiplied by their frequency of pixels value to get an overall value of wetness for the area. The frequency of pixel values provided quantitative information on how often each wetness value occurred in the remote sensing image. The overall values of wetness could then be converted into meaningful units, mm/day.

The newly calculated overall values of wetness for each year were then multiplied by its $\mathrm{ET}_{\mathrm{o}}$ computed earlier. The results give the overall $\mathrm{ET}$ for the area in each year. The $\mathrm{ET}_{\mathrm{o}}$ acts as a ceiling value, meaning that the highest $\mathrm{ET}$ rate for the given day for each year will be equal to the $\mathrm{ET}_{\mathrm{o}}$. When multiplying by the $\mathrm{ET}_{\mathrm{o}}$, the minimum value of ET will equal zero and the maximum value will equal the $\mathrm{ET}_{\mathrm{o}}$. The last step was to divide the overall ET for the area of each year by the total frequency of pixels to get the average regional ET rate.

Results

The calculated results for $\mathrm{ET}_{\mathrm{o}}$ started at $7.52 \mathrm{~mm} /$ day in 1999 and ended at 7.68 $\mathrm{mm} /$ day in 2009 (Table 1). During the time span for this study, the $\mathrm{ET}_{\mathrm{o}}$ reached its highest value of $8.3 \mathrm{~mm} /$ day in 2006 . Not surprisingly, the $\mathrm{ET}_{0}$ was the lowest at 7.06 $\mathrm{mm} /$ day in 2000 when the mean temperature was also at its lowest, $30^{\circ}$ Celsius. The hottest mean temperature and the highest $\mathrm{ET}_{\mathrm{o}}$ rate were produced in 2006. $\mathrm{ET}_{\mathrm{o}}$ is calculated by both incident solar radiation and mean temperature (Equation 5). Since the incident solar radiation is an average that was kept constant throughout the analysis, mean temperature heavily determined $\mathrm{ET}_{\mathrm{o}}$ rates. Hotter mean temperatures produced higher $\mathrm{ET}_{\mathrm{o}}$ rates. 
Table 1- Calculated $\mathrm{ET}_{\mathrm{o}}$ Per Year

\begin{tabular}{|c|c|c|c|c|}
\hline Date & $\begin{array}{c}\text { Mean Temp } \\
\text { (Celsius) }\end{array}$ & Precipitation & Incident Solar Radiation & $\begin{array}{l}\mathrm{ET}_{\mathrm{o}}=\text { pot. } \\
\mathrm{max} \\
(\mathrm{mm} / \text { day })\end{array}$ \\
\hline $7 / 04 / 1999$ & 33 & 0 & 26.532 & $\mathbf{7 . 5 2}$ \\
\hline $7 / 06 / 2000$ & 30 & 0 & 26.532 & 7.06 \\
\hline $7 / 09 / 2001$ & 32 & 0 & 26.532 & 7.37 \\
\hline $7 / 12 / 2002$ & 37 & 0 & 26.532 & $\mathbf{8 . 1 5}$ \\
\hline $7 / 05 / 2003$ & 34 & 0 & 26.532 & 7.68 \\
\hline $7 / 04 / 2004$ & 32 & 0 & 26.532 & 7.37 \\
\hline $7 / 12 / 2005$ & 36 & 0 & 26.532 & 7.99 \\
\hline $7 / 15 / 2006$ & 38 & 0 & 26.532 & $\mathbf{8 . 3 0}$ \\
\hline $7 / 02 / 2007$ & 36 & 0 & 26.532 & 7.99 \\
\hline $7 / 04 / 2008$ & 37 & 0 & 26.532 & $\mathbf{8 . 1 5}$ \\
\hline $7 / 07 / 2009$ & 34 & 0 & 26.532 & $\mathbf{7 . 6 8}$ \\
\hline
\end{tabular}

The calculated ET rates provided different results. The ET rate started at 3.34 $\mathrm{mm} /$ day in 1999 and increased to the highest value in 2001 at $4.18 \mathrm{~mm} /$ day (Table 2). After 2001, the ET rates slowly decreased and leveled off to $3.59 \mathrm{~mm} /$ day in 2009 . A small peak occurred in 2006 at $3.81 \mathrm{~mm} /$ day. The ET results were considerably lower than the $\mathrm{ET}_{\mathrm{o}}$ results. For the ET results to be similar to the $\mathrm{ET}_{\mathrm{o}}$ results, the time of day in which the remote sensing data were collected would have had to have been in the midafternoon when the outside temperatures were hotter. The time of day in which the data were collected is important, and is later discussed. 
Table 2- ET Rates

\begin{tabular}{|c|c|c|c|c|c|}
\hline Year & $\mathrm{ET}_{\circ}$ & Interval & $\begin{array}{c}\text { Total } \\
\text { Frequency }\end{array}$ & Overall ET & $\begin{array}{c}\text { ET Rate mm/day (Overall } \\
\text { ET/Total Frequency) }\end{array}$ \\
\hline 1999 & 7.68 & 0.042 & 2898589 & 9687107.50 & $\mathbf{3 . 3 4}$ \\
\hline 2000 & 8.15 & 0.036 & 2925169 & 10385356.84 & $\mathbf{3 . 5 5}$ \\
\hline 2001 & 7.99 & 0.048 & 2985597 & 12474552.80 & $\mathbf{4 . 1 8}$ \\
\hline 2002 & 8.30 & 0.050 & 3038595 & 12493534.75 & $\mathbf{4 . 1 1}$ \\
\hline 2003 & 7.99 & 0.056 & 3069552 & 11080441.53 & $\mathbf{3 . 6 1}$ \\
\hline 2004 & 7.37 & 0.044 & 2878126 & 10296836.61 & $\mathbf{3 . 5 8}$ \\
\hline 2005 & 7.68 & 0.040 & 2830910 & 9333623.19 & $\mathbf{3 . 3 0}$ \\
\hline 2006 & 8.15 & 0.036 & 2936263 & 11179023.07 & $\mathbf{3 . 8 1}$ \\
\hline 2007 & 7.37 & 0.035 & 2966607 & 10031183.84 & $\mathbf{3 . 3 8}$ \\
\hline 2008 & 7.06 & 0.040 & 2844726 & 10374485.88 & $\mathbf{3 . 6 5}$ \\
\hline 2009 & 7.52 & 0.030 & 2999989 & 10782921.15 & $\mathbf{3 . 5 9}$ \\
\hline
\end{tabular}

The wetness tasseled cap histograms also produced results that showed the change of wetness over the eleven-year time span throughout the landscape. The complete wetness histograms spanning from 1999 to 2009 are shown in Appendix A; these histograms plot the number of pixels present in the image for each wetness value. Figure 6 is the wetness histogram for 2005. The x-axis charts the degree, or amount, of wetness. As the $\mathrm{x}$-axis increases, so does the amount of wetness. Arid and dry lands are represented on the left portion of the x-axis. The y-axis plots the amount of pixels, or pixel frequency, in the remote sensing image. The 2005 wetness histogram contains a high pixel frequency for drier lands (Figure 6). The pixel frequency drops as the wetness values increase. The tasseled cap histograms are further analyzed in the discussion section of the document. 


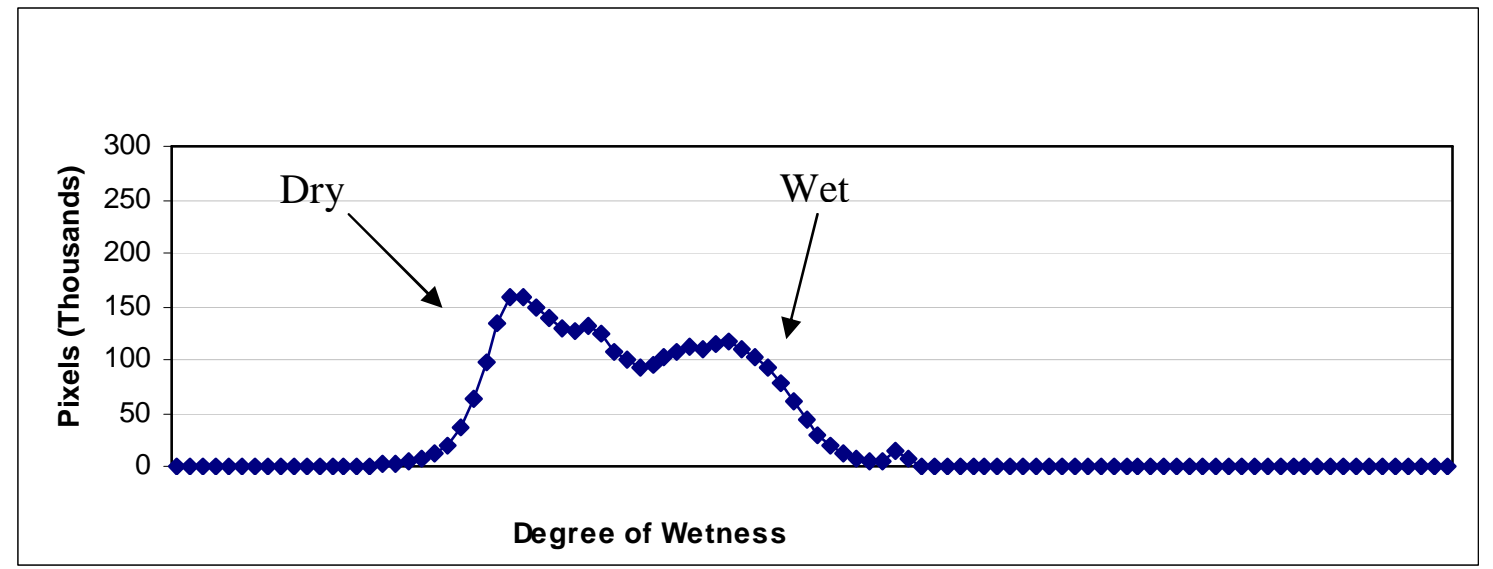

Figure 6: 2005 Wetness Tasseled Cap Histogram 


\section{DISCUSSION AND CONCLUSION}

The results from the ET rates produced an interesting peak in the graph (Figure 7) in 2001 and 2002. The ET rates for 2001 and 2002 appeared as outlying results in this study. At first, it was thought that this peak was caused by delays in implementing the Water Smart Landscape Program in 1999. An increase in ET rates may have occurred for the first few years as the program slowly developed. However, it is concluded that the peak in ET rates was not caused by the implementation of the Water Smart Landscape Program, but instead by weather conditions.

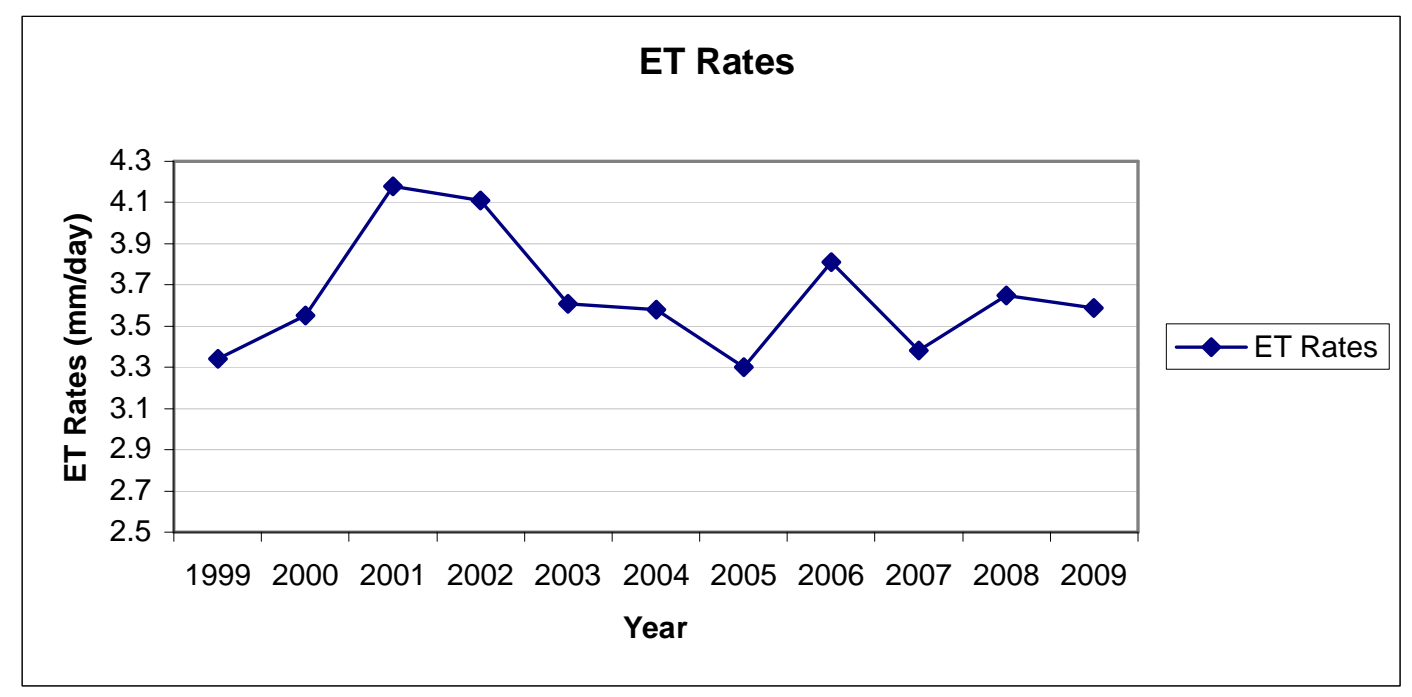

Figure 7: Calculated ET Rates

Three days prior to the July 2001 date, it rained 0.39 inches in the Las Vegas metropolitan area (Weather Underground, 2010). Rain and thunderstorms were also recorded for the July 2002 date, despite clear conditions when the image was captured. The wet soil for both years consequently would increase ET rates. The wetness histograms from 2001 and 2002 changed shape as well (Figure 8). The overall change in 
the shape of the histograms from 2001 to 2002 seemed to correspond with the presence of precipitation. The total mean ET rates for the region decreased after 2002 but show a small upward peak in 2006 (Figure 7). Although no precipitation occurred during the week in 2006, both the $\mathrm{ET}_{\mathrm{o}}$ and mean temperature were the highest in 2006. The increase in temperature caused an increase in ET rates. With the exceptions of 2001 and 2002, the ET rates remained stable with slight increases and decreases throughout the study.
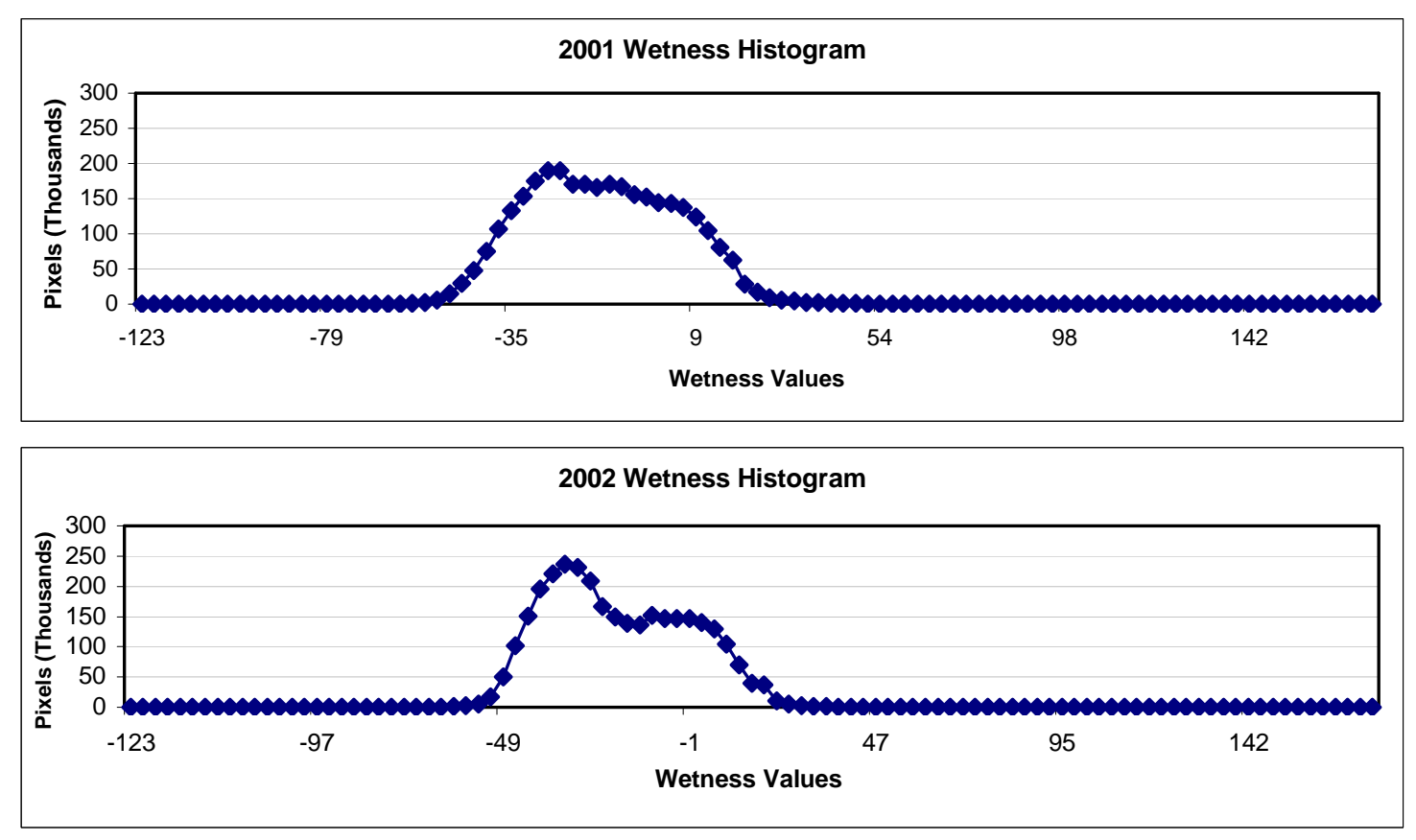

Figure 8: 2001 and 2002 Wetness Histograms

Figure 9 is a modified wetness histogram of 1999 and 2009 that contains only the minimum to maximum wetness values used in the analysis. The modified histograms are a specific portion of the overall histograms. Although detecting the change in shape between the 1999 and 2009 is much more apparent in the overall histograms, the modified histograms allow for a specific concentrated on the key wetness values. The shape of the 1999 wetness histogram has a predominant peak that occurs just under 
200,000 pixels (Figure 9). Once the 1999 histogram hits its peak, the graph gradually decreases. Unlike the 1999 wetness histogram with one larger broad peak, the 2009 wetness histogram contains two subtle smaller peaks (Figure 9). The two broad peaks occur around 110,000 pixels, considerably lower than the 1999 wetness histogram pixel frequency. The slight trough between peaks most likely is where a transition from drier to wetter areas transpires. This occurs at a wetness value of about -32 for 1999 and -54 for 2009 (Figure 9). The 1999 image seems to have larger dry areas, due to the higher pixel frequency in the dry, left-hand portion of the distribution, with a more distinctive transition to wet areas. The wetter areas in both 1999 and 2009 have similar pixel frequencies of around 110,000 . It is difficult to determine exactly what differences occur between the two years. The 1999 histogram is much more sporadic, whereas the 2009 histogram is very consistent. However, the regional average calculated ET rates for the two years were very close with 1999 at $3.34 \mathrm{~mm} / \mathrm{day}$ and 2009 at $3.59 \mathrm{~mm} /$ day. The modified histograms were used to provide a different perspective and a more detailed look at wetness values between the start and end years of the study. 

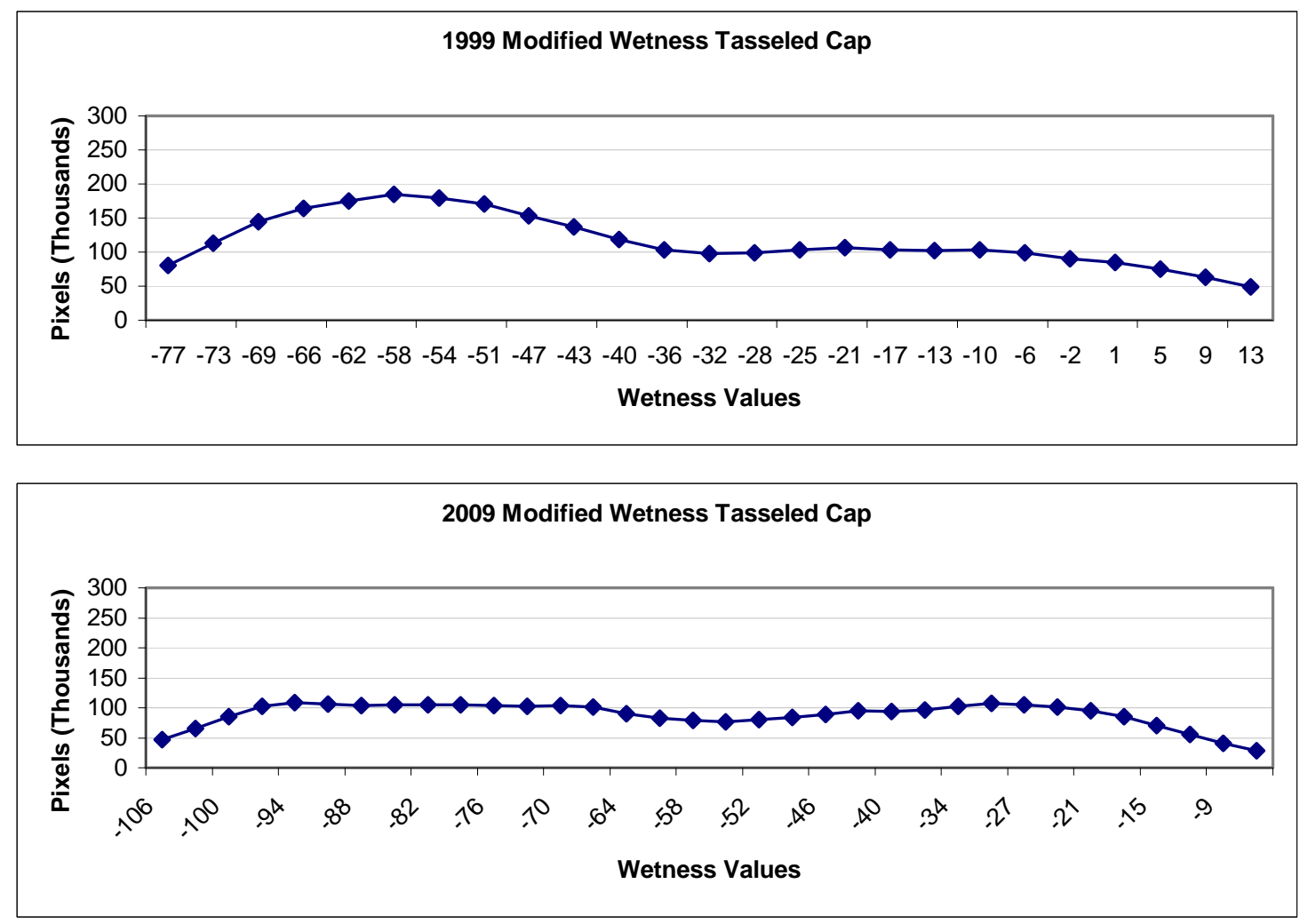

Figure 9: 1999 and 2009 Modified Wetness Histograms

As mentioned earlier, the time of day in which the remote sensing data were collected was very important for the ET results. The remote sensing satellite scenes used in the study were taken in the early morning around $10 \mathrm{am}$. ET rates are lower in the early morning than in the afternoon when temperatures are hotter. The $\mathrm{ET}_{\mathrm{o}}$ results range from $7.06 \mathrm{~mm} /$ day to $8.3 \mathrm{~mm} /$ day, values that occur in the afternoon when temperatures increase. The ET rates range from $3.3 \mathrm{~mm} /$ day to $4.18 \mathrm{~mm} /$ day, which reflects the early morning time that the remote sensing images were taken. To help provide validity to the ET results, findings from a study conducted to calculate hourly $\mathrm{ET}_{\mathrm{o}}$ showed that in Logan, Utah on August 2, 1990 the ET $_{\text {o }}$ was $1.42 \mathrm{~mm}$ at 10 am (Allen et al., 2006). Although slightly cooler than Las Vegas, Logan has hot summers with some precipitation. The temperature in Logan was $60^{\circ}$ Fahrenheit at $10 \mathrm{am}$. The ET rates 
calculated for Las Vegas are higher than Logan but the average temperature at 10 am in July in Las Vegas is around $90^{\circ}$ Fahrenheit (Weather Underground, 2010). The thirtydegree difference in temperature explains the higher ET rates in Las Vegas. The time of day is an extremely important factor on how much ET occurs, but a valid comparison can be made between locations at the same time of day.

Other methods of estimating ET were tested as part of this study but were unsuccessful. The first method was a land-water mask using NDVI. Each year's NDVI histogram was used to differentiate water values from land values. Once distinguished, a mask was created to calculate areas where both water and land values occurred in the same setting. The results were not used because they calculated the total area in square meters where land and water occurred. The land-water mask did not produce results on the frequency of wetness in the land. Another method tried was applying a gaussian filter to calculate ET rates. A gaussian filter is a process that smoothes the image by calculating weighted averages in a moving filter box. Three different weather stations provided ET data over the past twenty years for each of their specific location. A gaussian filter was applied to the wetness tasseled cap transformation to determine if a correlation existed between the actual ET values and the ET values calculated in this study. This provided a means of smoothing pixel values in order to see whether their correlation with direct point observations improved. They did not, so this method was not pursued.

A further extension of this study would be to examine and compare ET rates of individual neighborhoods. Since the study examined the region as a whole, comparing 
neighborhoods could provide a more detailed analysis for water planners. An interesting neighborhood is the Summerlin area, located in the western part of Las Vegas. Figure 10 provides a qualitative wetness tasseled cap comparison of the Summerlin area in 1999 and 2009. The two years are set to the same wetness value scale. The orange, red, and purple colors are characterized as areas with little or no ET. Areas with moderate ET rates are represented in yellow and areas in green correspond with high ET rates. Based on the comparison, 1999 has significantly more green areas on the map (Figure 10). However, a lot of land had not been developed in 1999. Interestingly, in 2006 the Red Rock Casino and Resort opened in Summerlin. Development quickly took place to attract more residents and visitors to the area. By 2009 the area dramatically increased in population. The population growth from 1999 to 2009 in Summerlin is apparent in Figure 10. Areas that are green in 1999 appear as yellow in 2009. Although the average ET rates seem lower in 2009 than 1999, the change in wetness values and colors between the two years are not necessarily due to a decrease in average ET rates. Meteorological impacts and climatic factors can alter tasseled cap transformations the same way they can alter wetness histograms. An in-depth neighborhood analysis with more detailed data would be a great extension to the study, as it would provide a better understanding of ET rates on a smaller scale. 


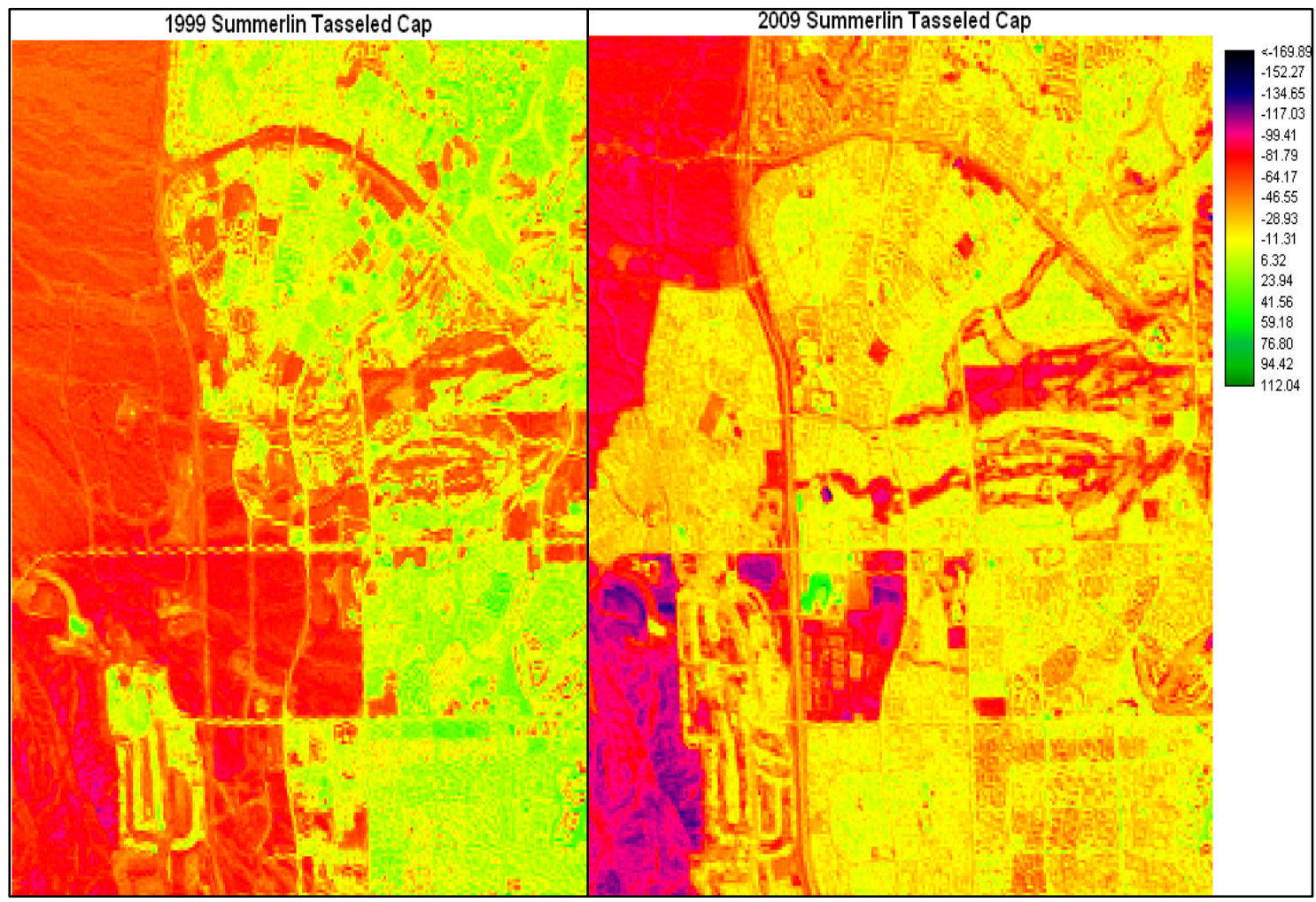

Figure 10: Comparison of 1999 and 2009 Summerlin Tasseled Cap

In summary, it is important to note that the study is a snapshot in time of a set of particular days. Results are based on a specific time of day rather than an average or integration over the day or month. The time of day in which a remote sensing image is captured affects ET results. Lower ET rates would occur at night and in the early morning when temperatures are lower. Higher ET rates would occur in the midafternoon when temperatures are at their highest. Climatic factors also play a huge role in the outcome of the results. For example, if the soil were saturated due to rain, the ET rates would be higher. Both the time of day and climatic factors can alter ET rates. Nevertheless, if properly calibrated, remotely sensed data can be very helpful in analyzing ET rates and in showing how they change over time within any given region. 


\section{Conclusion}

The results discussed here support the thesis that ET rates are affected both by weather conditions and water policy. Precipitation and severe hot weather caused the largest increase in the ET results in 2001, 2002, and 2006. Extreme weather conditions significantly altered the ET rates. However, the ET rates steadied out and remained fairly stable around $3.5 \mathrm{~mm} /$ day to $3.7 \mathrm{~mm}$ /day over the rest of the decade, when conditions were generally average for each captured date. The Water Smart Landscape Program seemed to have played a role in keeping the ET rates constant. During the eleven-year time span, the population increased 18.6\% (City Data, 2010). Although ET rates did not decrease over time, the ET rates did not significantly increase with a steady growth in population (Figure 11). With such a steady growth in population, it is expected that ET would have significantly increased as well

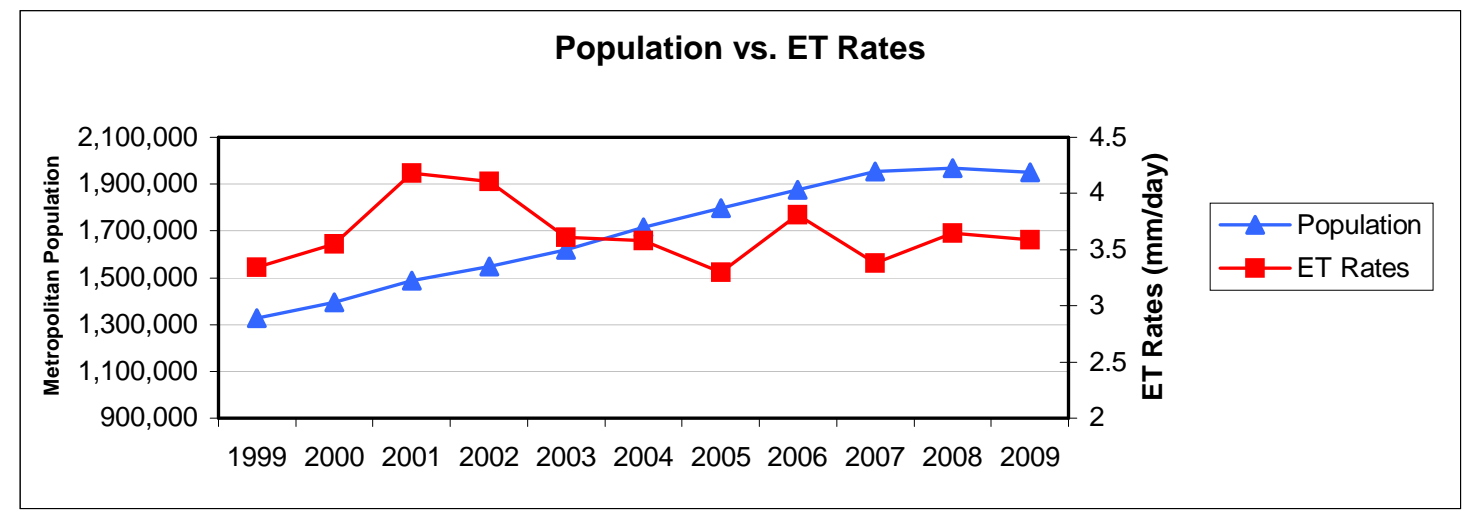

Figure 11: Las Vegas Metropolitan Population vs. ET

The implementation of the Water Smart Landscape Program was likely a big reason that ET rates stayed fairly constant for the region. The Water Smart Landscape Program was not solely the only reason why ET rates remained stable. The SNWA 
created other conservation methods that likely contributed to the success. However, the Water Smart Landscape Program was the biggest conservation method employed to limit outdoor water usage. To fully understand how weather conditions and the Water Smart Landscape Program alter ET rates, it would be best to examine multiple days within each month. Due to the return time of the Landsat satellite it was not possible. Nevertheless, this study proved it was possible to use Landsat satellite images to obtain adequate ET results. 


\section{APPENDIX A: WETNESS HISTOGRAMS}
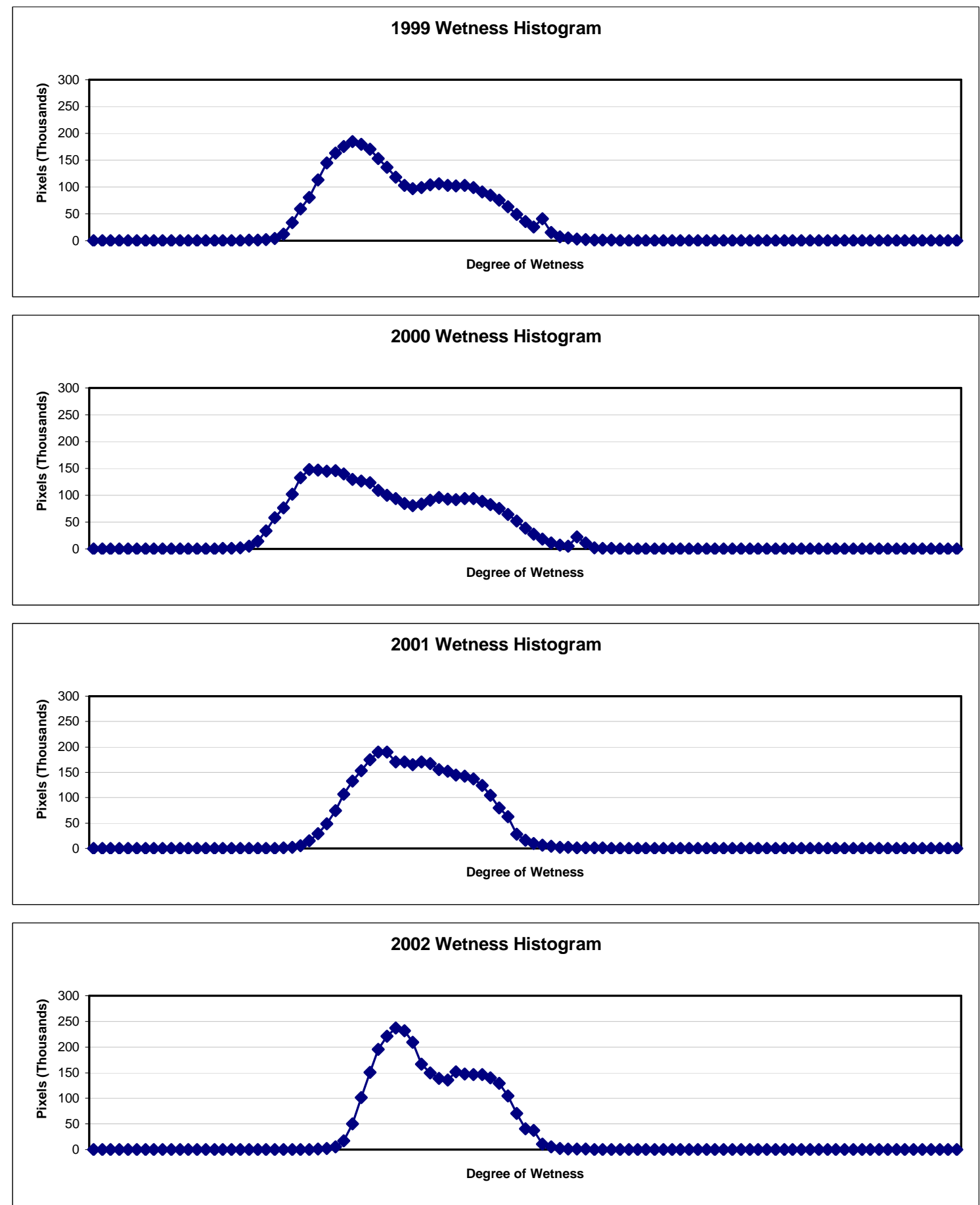

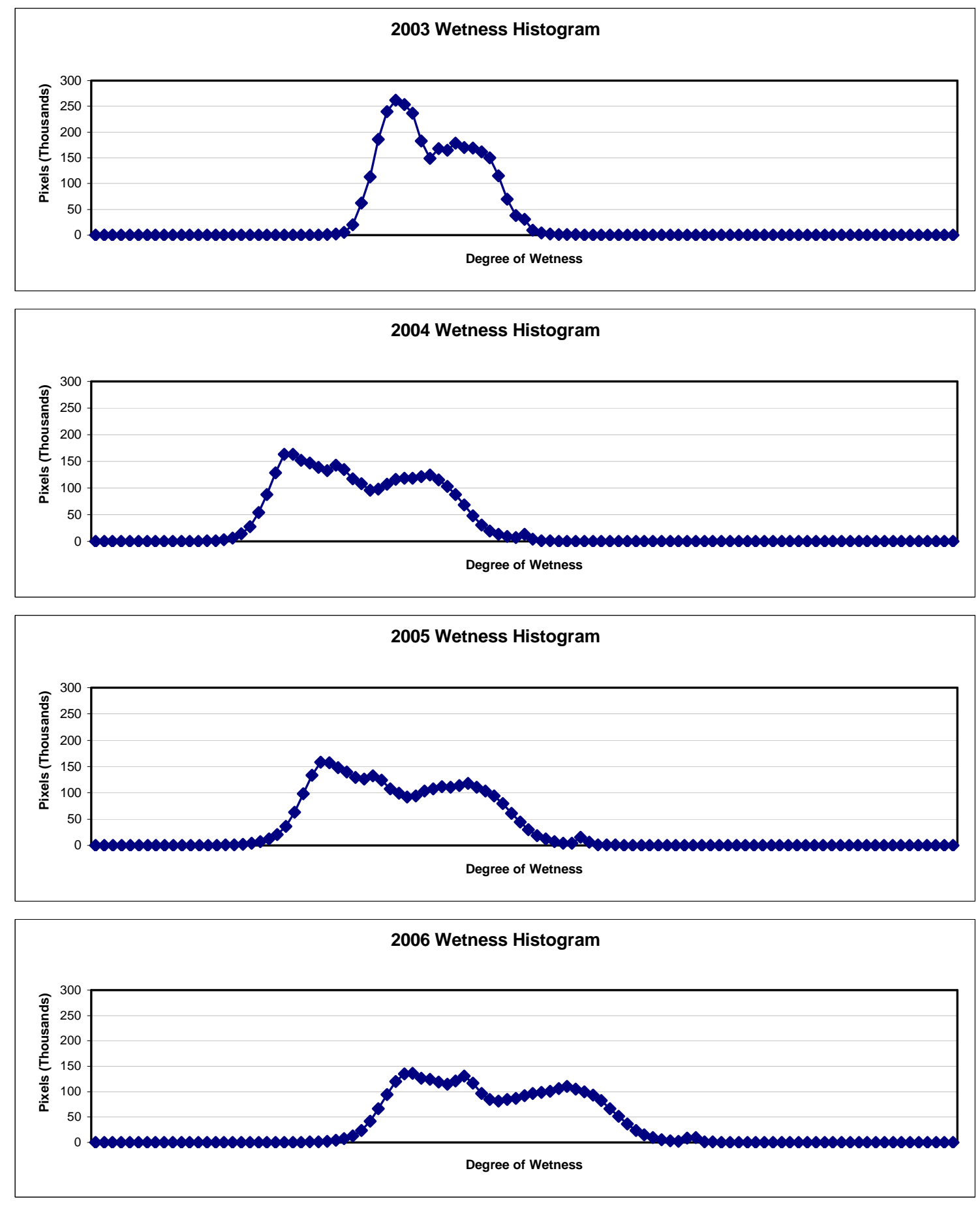

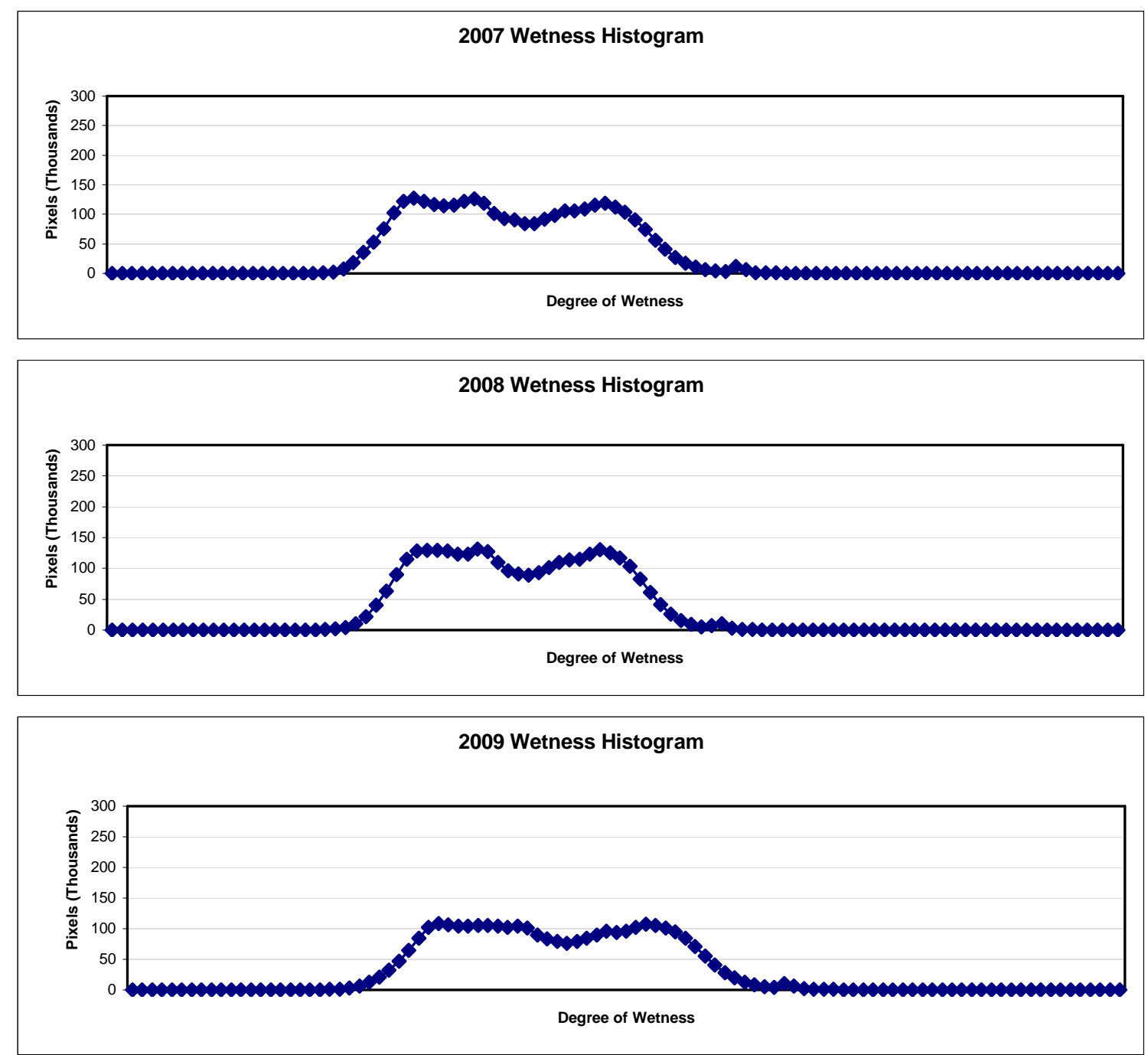


\section{APPENDIX B: TASSELED CAP MAPS}

1999 Wetness Tasseled Cap

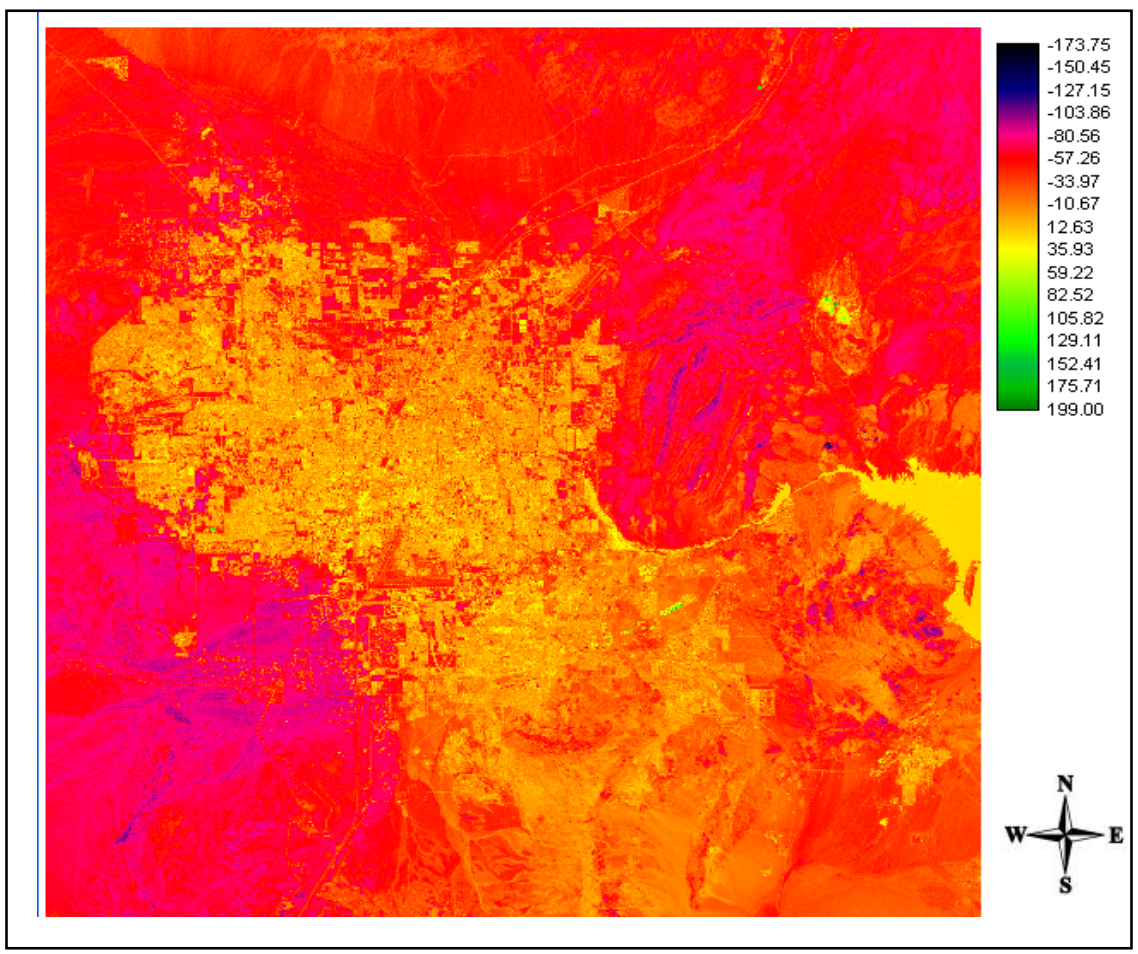

2000 Wetness Tasseled Cap

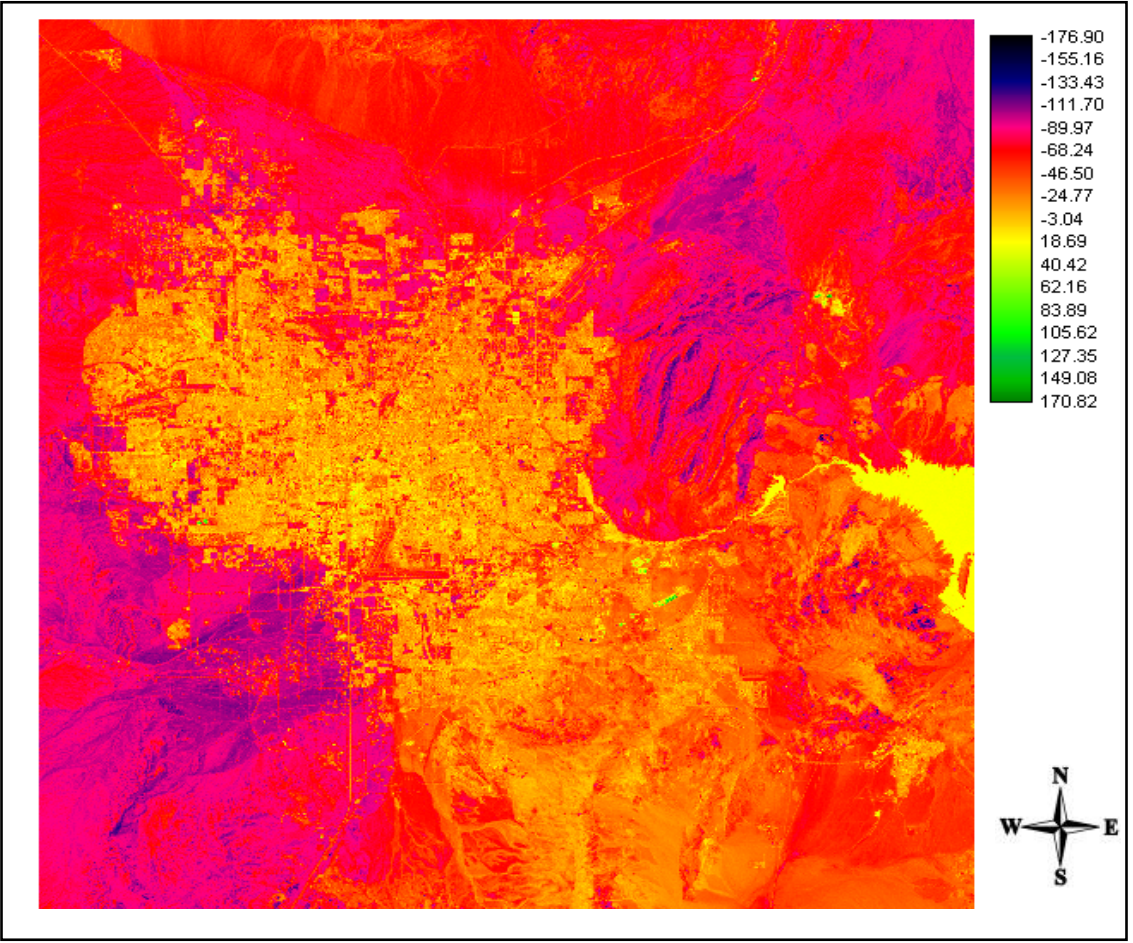


2001 Wetness Tasseled Cap

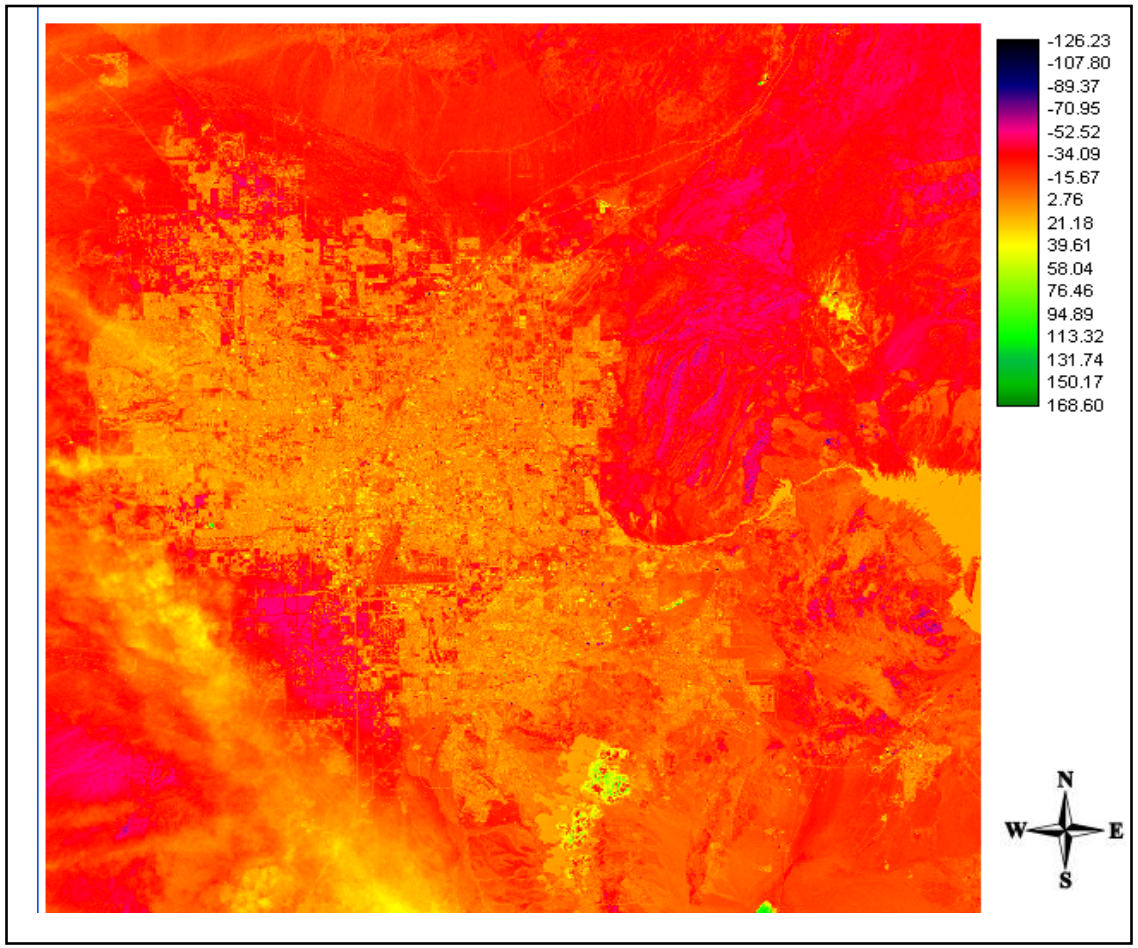

2002 Wetness Tasseled Cap

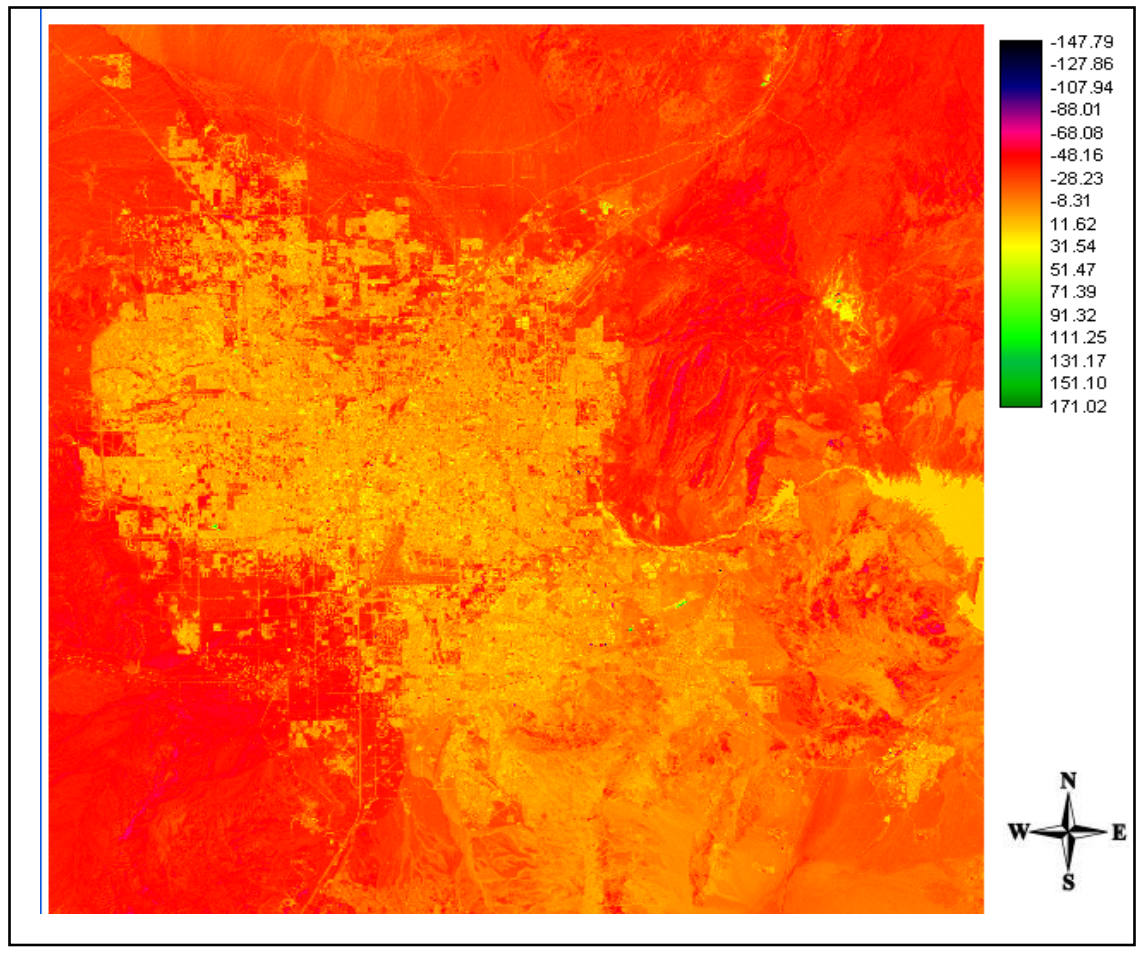




\section{Wetness Tasseled Cap}

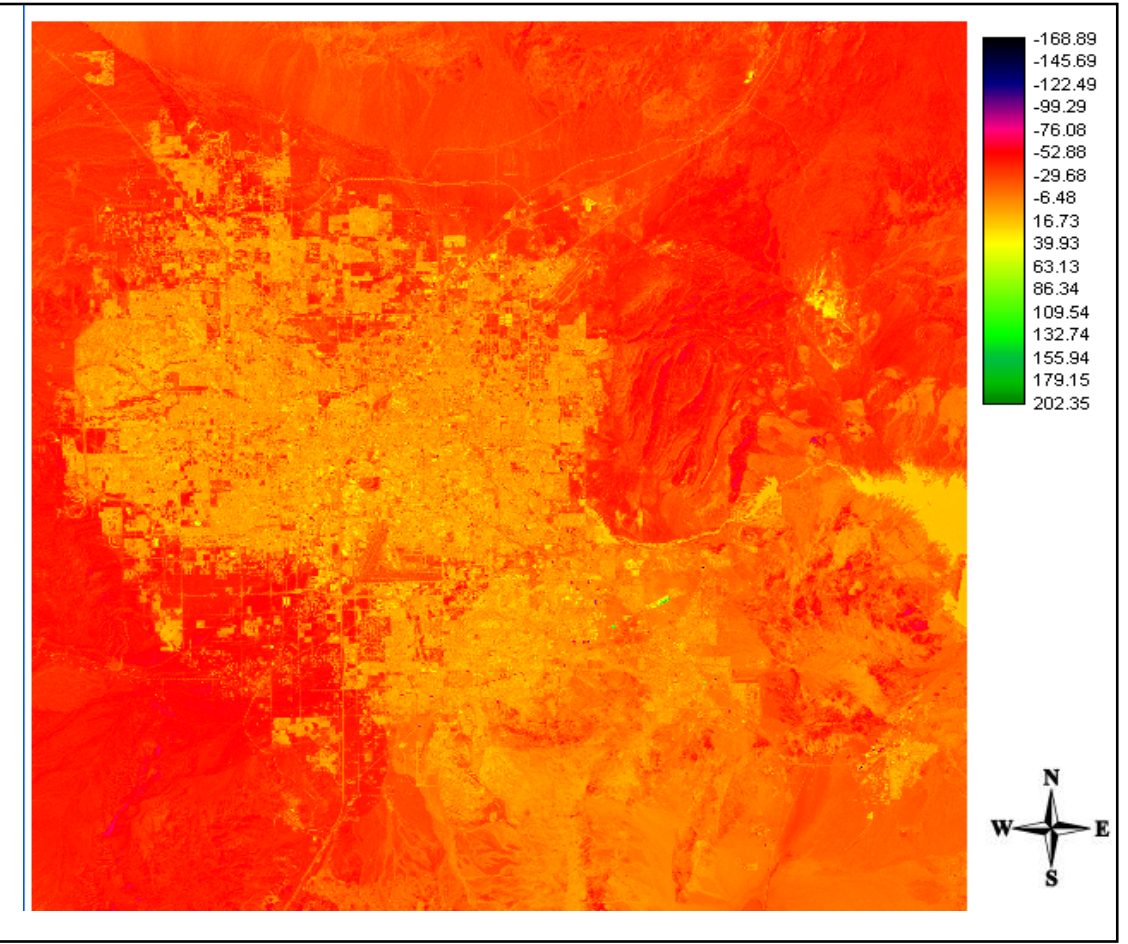

2004 Wetness Tasseled Cap

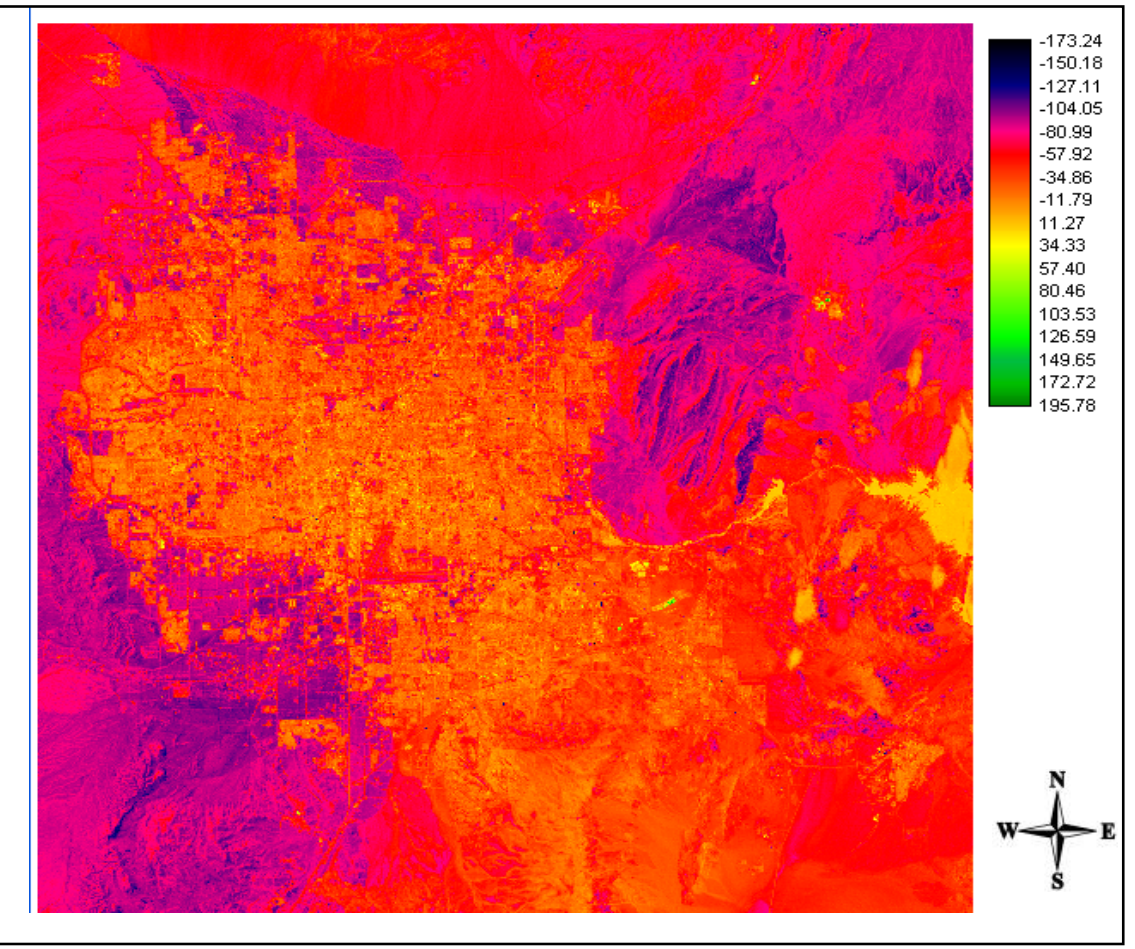


2005 Wetness Tasseled Cap

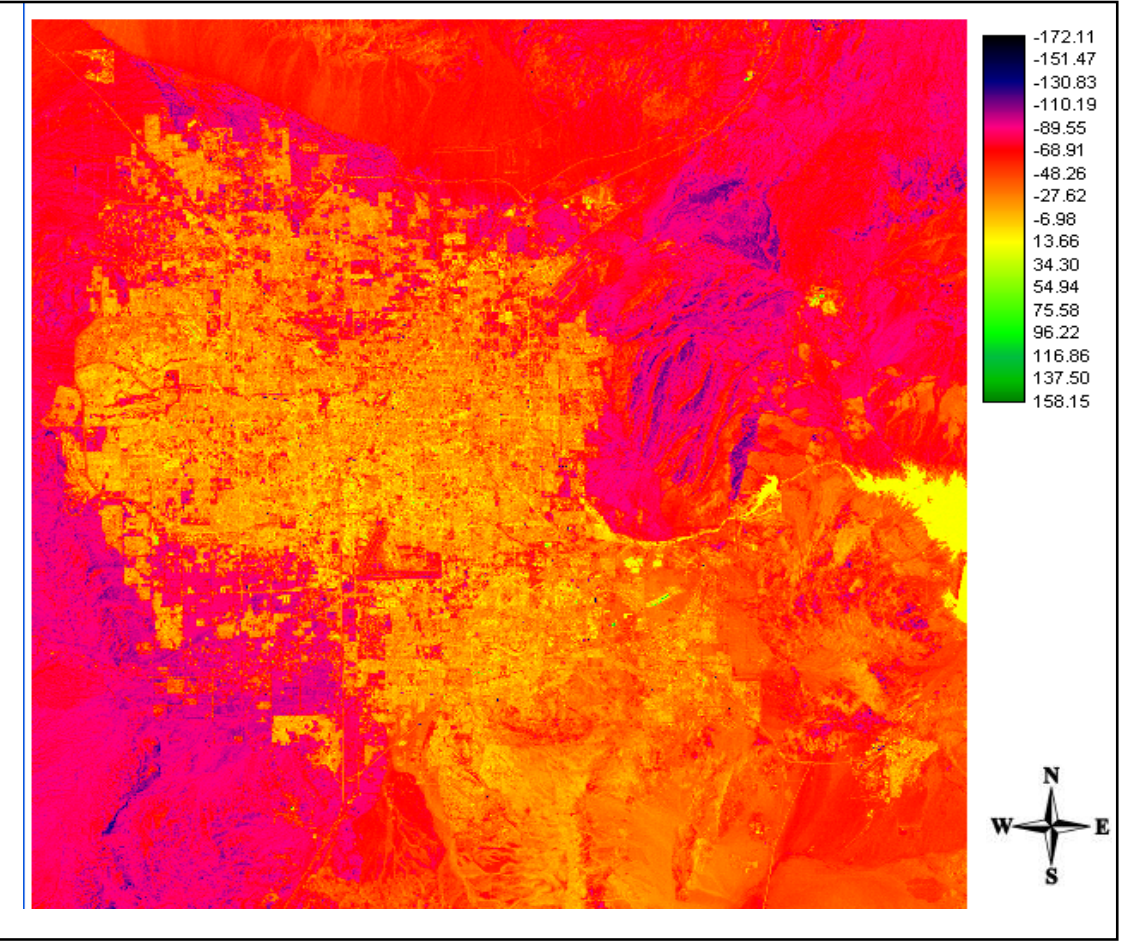

2006 Wetness Tasseled Cap

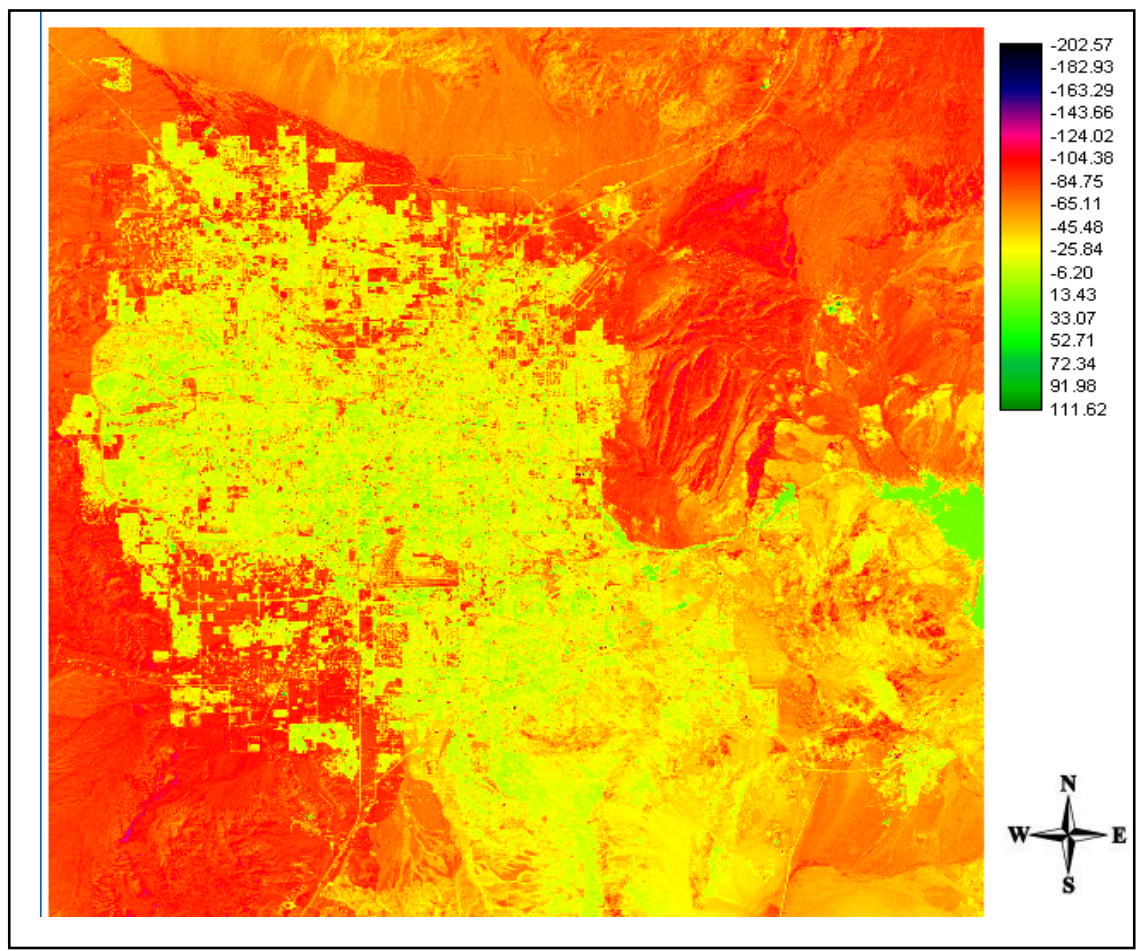


2007 Wetness Tasseled Cap

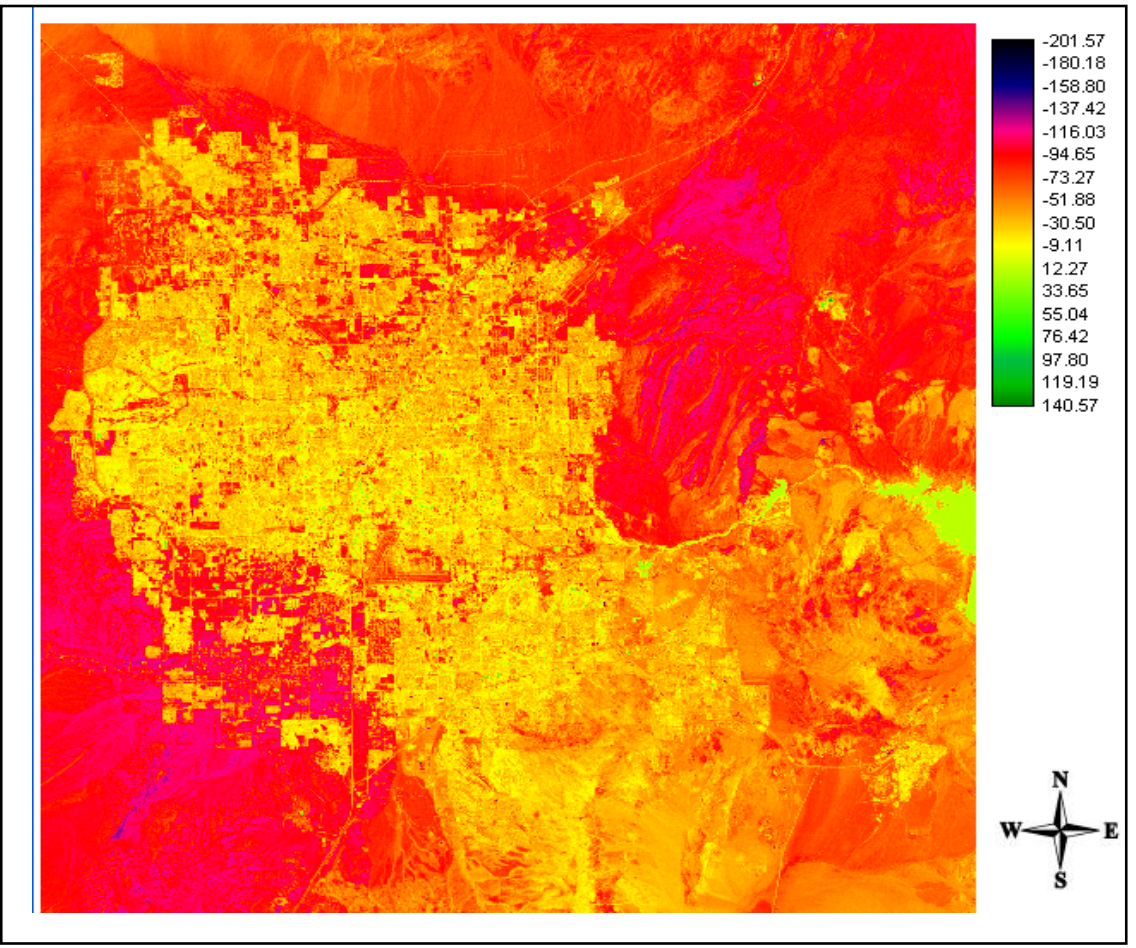

2008 Wetness Tasseled Cap

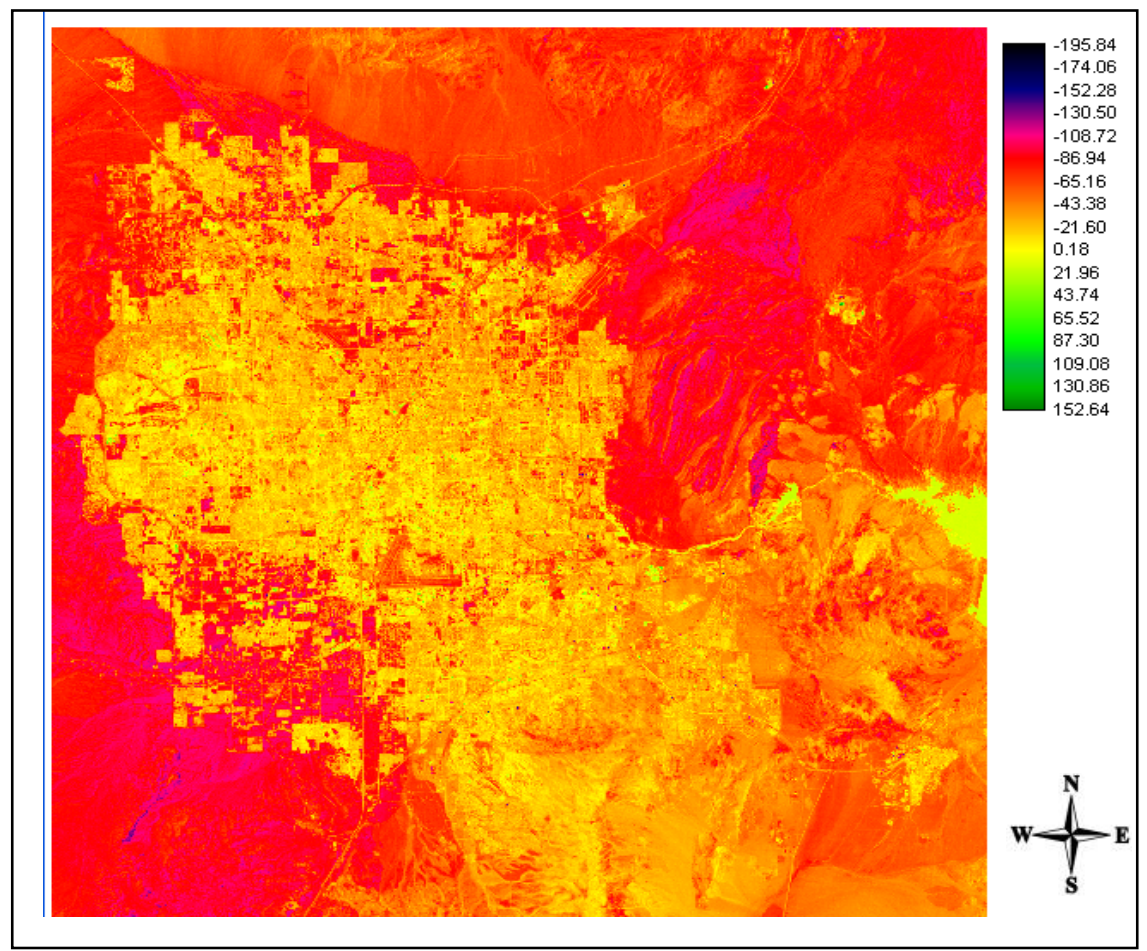


2009 Wetness Tasseled Cap

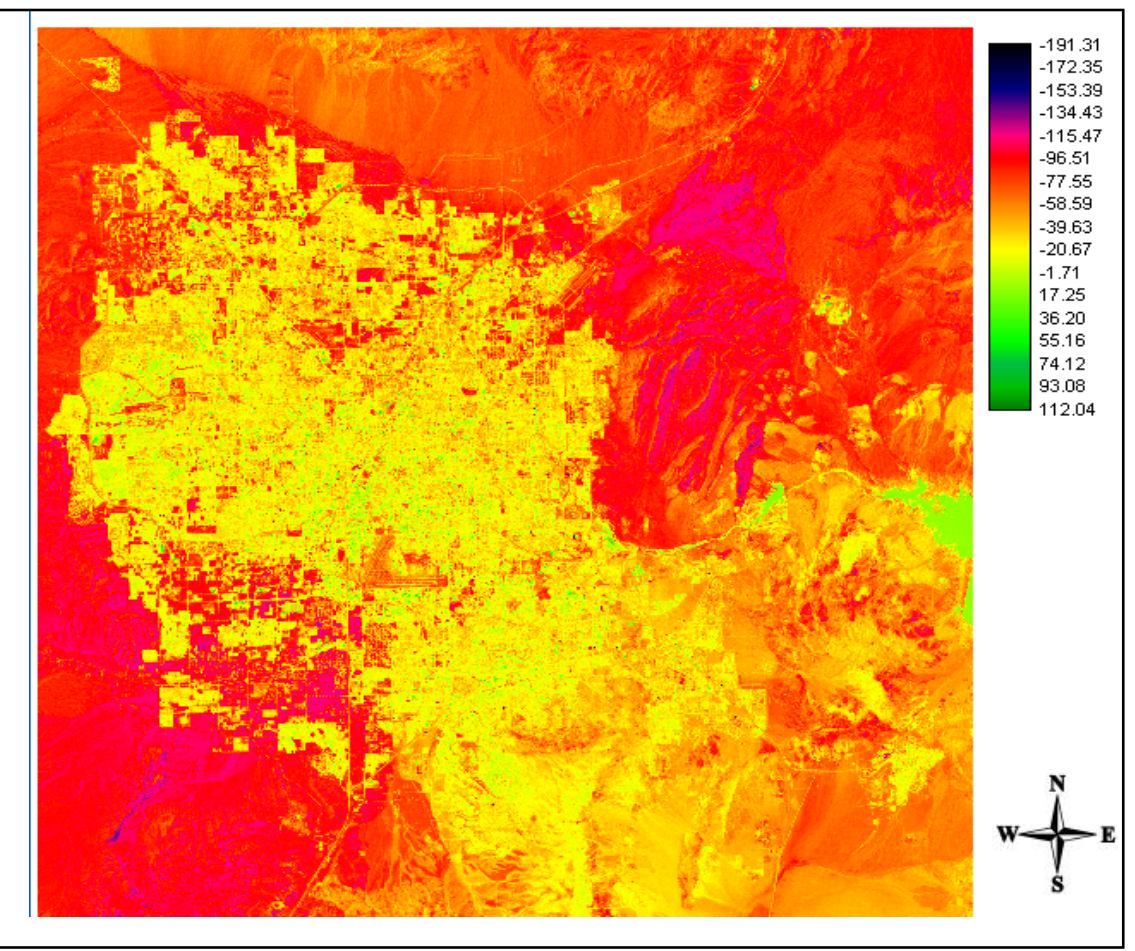




\section{REFERENCES}

Allen, Richard G., William O. Pruitt, James L.Wright, Terry A. Howell, Francesca Ventura, Richard Snyder, et al. 2006. "A Recommendation on Standardized Surface Resistance for Hourly Calculation of Reference ETo by FAO 56 Penman-Monteith method." Agricultural Water Management 81: 1-22.

Batra, Namrata., Shafiqul Islam, Virginia Venturini, Gautam Bisht and Le Jiang. 2006. "Estimation and Comparison of Evapotranspiration from MODIS and AVHRP Sensors for Clear Sky Days Over the Southern Great Plains." Remote Sensing of Environment 103: 1-15.

Campbell, James. 2002. Introduction to Remote Sensing. New York: Guildord Press.

City Data. 2010. “Las Vegas, Nevada.” Accessed March 3, 2010. http://www.citydata.com/city/Las-Vegas-Nevada.html

City of Henderson. 2010. “Community Development.” Accessed November 15, 2010. http://www.cityofhenderson.com/community_development/open_space_and_trails_plan. php

Folhes, M.T., C.D Renno and J.V Soares. 2009. "Remote Sensing for Irrigation Water Management in the Semi-Arid Northeast of Brazil." Agricultural Water Management 96: 1398-1408.

Groeneveld P. David, William M. Baugh, John S. Sanderson and David J. Sanderson. 2007. "Annual Groundwater Evapotranspiration Mapped From Single Satellite Scenes." Journal of Hydrology 344: 146-156.

Hargreaves, G.H. and Z.A. Samani. 1982. "Estimating Potential Evapotranspiration." Journal of Irrigation and Drainage Engineering 108: 223-230.

Jenson, John. 2007. Remote Sensing of the Environment. Upper Saddle River: Pearson.

Krystyna A. Steve. 2001. "A system dynamics model to facilitate public understanding of water management options in Las Vegas, Nevada." Journal of Environmental Management 4: 303-313.

Las Vegas Wash Coordination Committee (LVWCC). 2000. "Las Vegas Wash Comprehensive Adaptive Management Plan.” Accessed February 3, 2010.

http://www.lvwash.org/html/resources_library_lvwcamp.html

Li, Fuqin and T.J Lyons. 2002. "Remote Estimation of Regional Evapotranspiration." Environmental Modeling \& Software 17: 61-75. 
Morris. R.L and D.A Devitt. 2004. "Managing Landscape Water Use in the Las Vegas Valley: Potential ET." Accessed January 15, 2010.

http://www.unce.unr.edu/publications/files/nr/2002/FS0290.pdf

Mutiga, Jennifer Kinoti, Zhongbo Su and Tsahaei Woldai. 2009. "Using satellite remote sensing to assess evapotranspiration: Case study of the upper Ewaso Ng'iro North Basin, Kenya." International Journal of Applied Earth Observation and Geoinformation 283: 19.

Narongrit, C. and Y. Yasuoka. 2003. "The Use of Terra-MODIS Data for Estimating Evapotranspiration and Its Change Caused By Global Warming." Environmental Informatics Archives 1: 505-511.

National Aeronautics and Space Administration (NASA). 2010. "Surface Meteorology and Solar Energy." Accessed October 13, 2010. http://eosweb.larc.nasa.gov/sse/

Pacific Institute. 2007. "Hidden Oasis: Water Conservation and Efficiency in Las Vegas." Accessed January 17, 2010. http://www.pacinst.org/reports/las_vegas/hidden_oasis.pdf

Southern Nevada Water Authority (SNWA). 2009. "Conservation Plan 2009-2013." Accessed January 29, 2010. http://www.snwa.com/assets/pdf/cons_plan.pdf

Southern Nevada Water Authority (SNWA). 2010. "Water Use Facts.” Accessed January 13, 2010. http://www.snwa.com/html/cons_waterfacts.html

Sovocool A. Kent. 2005. "Xeriscape Conversion Study Final Report.” Accessed January 29, 2010. http://www.snwa.com/assets/pdf/xeri_study_final.pdf

Western Resource Advocates. 2005. "Smart Water Report. Urban Sprawl: Impacts on Urban Water Use." Accessed February 3, 2010.

http://www.westernresourceadvocates.org/media/pdf/SWChapter4.pdf

Xian, George and Mike Crane. 2006. "An Analysis of Urban Thermal Characteristics and Associated Land Cover in Tampa Bay and Las Vegas Using Landsat Satellite Data." Remote Sensing of Environment 104: 147-156.

Weather Underground. 2010. "Weather History.” Accessed November 1, 2010. http://www.wunderground.com/history/

Wu, I-Pai. 1997. “A Simple Evapotranspiration Model for Hawaii: The Hargreaves Model.” Engineers Notebook 106: 1-2. 